\title{
Thermoeconomic Evaluation and Optimization of Using Different Environmentally Friendly Refrigerant Pairs for a Dual-Evaporator Cascade Refrigeration System
}

\author{
Kasra Mohammadi ${ }^{1}$ and Kody M. Powell ${ }^{1,2, *(D)}$ \\ 1 Department of Chemical Engineering, University of Utah, 50 South Central Campus Drive, 3290 MEB, \\ Salt Lake City, UT 84112-9203, USA; kasra278@gmail.com \\ 2 Department of Mechanical Engineering, University of Utah, 1495 E 100 S, Salt Lake City, UT 84112-9203, USA \\ * Correspondence: kody.powell@utah.edu
}

Citation: Mohammadi, K.; Powell, K.M. Thermoeconomic Evaluation and Optimization of Using Different Environmentally Friendly Refrigerant Pairs for a Dual-Evaporator Cascade Refrigeration System. Processes 2021, 9, 1855. https://doi.org/10.3390/ pr9101855

Academic Editor: Luis Puigjaner

Received: 6 September 2021

Accepted: 14 October 2021

Published: 19 October 2021

Publisher's Note: MDPI stays neutral with regard to jurisdictional claims in published maps and institutional affiliations.

Copyright: (c) 2021 by the authors. Licensee MDPI, Basel, Switzerland. This article is an open access article distributed under the terms and conditions of the Creative Commons Attribution (CC BY) license (https:/ / creativecommons.org/licenses/by/ $4.0 /)$

\begin{abstract}
Applications of dual-evaporator refrigeration systems have recently gained much attention both in academia and industry due to their multiple benefits. In this study, a comprehensive thermodynamic and economic analysis is conducted to evaluate the potential of using several environmentally friendly refrigerant couples and identifies the most suitable one yielding the best economic results. To achieve this goal, a detailed parametric study is conducted, and an optimization process is performed using a particle swarm optimization (PSO) approach to minimize the unit production cost of cooling (UPCC) of the cascade refrigeration system. The results showed that among all selected 18 refrigerant pairs and for all ranges of examined operating parameters, the R170-R161 pair and R1150-R1234yf pair are identified as the best and worst pairs, respectively, from both thermodynamic and economic viewpoints. The results also confirm that R170-R161 pair has an improvement over R717-R744, used as a typical refrigerant pair of cascade refrigeration cycles. For a base case analysis, the COP of R170-R161 and R1150-R1234yf pairs is determined as 1.727 and 1.552 , respectively, while their UPCC is found to be $\$ 0.395 /$ ton-hr and $\$ 0.419 /$ ton-hr, respectively, showing the influence of proper selection of refrigerant pairs on the cascade cycle's performance. Overall, this study offers a useful thermodynamic and economic insight regarding the selection of proper refrigerant pairs for a dual-evaporator cascade vapor compression refrigeration system.
\end{abstract}

Keywords: dual-evaporator cascade refrigeration system; thermoeconomic analysis; optimization; refrigerant pairs; global warming potential; parametric study

\section{Introduction}

The industrial refrigeration sector is growing rapidly and its impacts on human life and within different industries cannot be underestimated. It is anticipated that the value of the global industrial refrigeration sector will grow to around $\$ 25$ billion by 2025 [1]. Growing demand and interest for developing innovative refrigeration systems, and increasing support from the government to improve the cold chain infrastructure, are the key drivers of industrial refrigeration sector growth [2]. However, the rapid growth of the refrigeration sector has caused some challenges due to the substantial energy consumption of refrigeration systems and negative environmental impacts of many refrigerants, such as their high global warming potential (GWP) [3-5]. Therefore, enhancing the performance of refrigeration systems and using low refrigerants with low GWP are two major routes towards mitigating the environmental impacts of refrigeration systems and providing significant carbon savings [6].

Cascade vapor compression refrigeration systems have been considered the most appealing type of refrigeration systems, especially for low-temperature applications where other refrigeration systems offer a low coefficient of performance (COP) [7,8]. A cascade refrigeration system comprises two separate refrigeration cycles thermally connected 
through a heat exchanger, called a cascade heat exchanger. A substantial number of studies have been presented in the literature regarding the potential performance improvement of cascade refrigeration cycles via several means and the selection of a more suitable refrigerant pair to achieve energy-saving and address environmental concerns.

For example, Bingming et al. [9] examined the performance of $\mathrm{NH}_{3} / \mathrm{CO}_{2}$ cascade refrigeration system using an experimental study. They conducted a parametric study to investigate the performance of several parameters on the system performance. The cascade system performance was compared with a two-stage $\mathrm{NH}_{3}$ system and a single-stage $\mathrm{NH}_{3}$ system with and without an economizer. The results showed the superiority of the cascade cycle for an evaporating temperature of lower than $40^{\circ} \mathrm{C}$. Yari and Mahmoudi [10], proposed two $\mathrm{CO}_{2}$ cascade refrigeration cycles and evaluated their performance using a thermodynamic model. While both cycles consisted of an ejector-expansion transcritical cycle as the topping cycle and a sub-critical $\mathrm{CO}_{2}$ cycle as the bottoming cycle, in one of the cycles, a supercritical $\mathrm{CO}_{2}$ power cycle was used to recover the waste heat from the gas cooler of the topping cycle.

The results of this study showed that both cycles showed a COP improvement over a conventional cascade cycle and the cycle that used supercritical $\mathrm{CO}_{2}$ power cycle for waste energy recovery had a better performance. Sarkar et al. [11] performed a thermodynamic analysis and optimization to identify the most suitable refrigerant pairs for a cascade refrigeration system. They evaluated the suitability of eight refrigerants and 56 possible combinations of refrigerant pairs using COP as a criterion. They found that propane-ammonia and propylene-ammonia are the best refrigerant pairs for higher evaporator temperatures and ethane-propylene is the best refrigerant pair for lower evaporator temperatures.

Aghazadeh Dokandari et al. [12] evaluated the use of ejectors in a cascade refrigeration cycle that used ammonia-carbon dioxide $\left(\mathrm{NH}_{3}-\mathrm{CO}_{2}\right)$ refrigerant pair from a thermodynamic perspective. It was shown that using ejectors in the cycle can improve the COP of the cascade refrigeration cycle up to $7 \%$. The results showed that the proposed ejector-based cascade refrigeration cycle has a promising application. Yilmaz et al. [13] carried out a thermodynamic analysis to evaluate the performance of a cascade refrigeration cycle that used $\mathrm{CO}_{2}-\mathrm{R} 404 \mathrm{a}$ refrigerant pair. The authors performed a parametric study to identify the optimum operating conditions of the cycle and maximize the COP. They showed that the maximum COP was obtained when the cascade condenser and primary condenser temperatures were equal to $-5{ }^{\circ} \mathrm{C}$ and $25{ }^{\circ} \mathrm{C}$, respectively. Parmar and Kapadia [14] thermodynamically evaluated the performance of a cascade refrigeration system for a supermarket application and examined the potential of using six refrigerants in the hightemperature cycle and R744 in the low-temperature cycle. They studied the influence of several operating parameters on the COP of the system and found R717-R744 as the most suitable refrigerant pair. Llopis et al. [15] evaluated five two-stage cascade refrigeration systems and examined the potential of using different low GWP refrigerants in these systems. The authors analyzed the systems' performance thermodynamically over a wide range of evaporator and ambient temperature conditions. They concluded that the cascade refrigeration systems that used $\mathrm{CO}_{2}$ as a low-temperature refrigerant have a promising application. In addition, the application of direct $\mathrm{CO}_{2}$ transcritical systems is not appealing for warm climates. Llopis et al. [16] evaluated the performance of a cascade refrigeration cycle that used two internal cascade heat exchangers and used $\mathrm{R} 134 \mathrm{a} / \mathrm{CO}_{2}$ as a refrigerant pair. They conducted an evaluation based on experimental results for evaporator and condenser temperatures ranging from $-40{ }^{\circ} \mathrm{C}$ to $-30{ }^{\circ} \mathrm{C}$ and from $30{ }^{\circ} \mathrm{C}$ to $50^{\circ} \mathrm{C}$, respectively. The authors concluded that using the second cascade heat exchanger caused a slight reduction in the cooling capacity of the system, but it increased the COP up to $3.7 \%$. Mosaffa et al. [17] carried out exergoeconomic and environmental analyses to evaluate two $\mathrm{CO}_{2} / \mathrm{NH}_{3}$ cascade refrigeration cycles: the first one was equipped with two flash tanks and the second one was equipped with a flash tank and a flash intercooler. A comparative analysis was conducted to examine and compare the performance of the 
systems and identify the optimum operating parameters. The results showed that the annual cost rate of the first one could be over $11 \%$ lower than the second system. In addition, the results showed the potential benefits of these cascade refrigeration systems.

Megdouli et al. [18] proposed a novel ejector expansion transcritical cascade refrigeration cycle and evaluated its performance thermodynamically. In this cycle, two ejectors were used in the low and high-temperature cycles and a transcritical $\mathrm{CO}_{2}$ Rankine cycle was used to recover the available heat in the condensation stage of the high-temperature cycle of the refrigeration system. $\mathrm{CO}_{2}$ and nitrous oxide $\left(\mathrm{N}_{2} \mathrm{O}\right)$ were used as refrigerants in the high-temperature and low-temperature cycles of the system. A COP improvement of over $9 \%$ was reported for the novel system compared to a typical ejector expansion cascade refrigeration cycle. Sun et al. [19] evaluated the potential of 28 low GWP refrigerant pairs for a typical cascade refrigeration cycle from a thermodynamic viewpoint. They showed that, among the examined refrigerant pairs, the R41/R161 and R170/R161 refrigerant pairs are the best options. The authors also recommended the use of R41/R161 as the most suitable pair for the evaporator temperature of higher than $-60^{\circ} \mathrm{C}$. Sun et al. [20] conducted a thermodynamic analysis to evaluate the potential of using different low GWP potential refrigerants for a three-stage cascade refrigeration system. The results of their study showed that R1150 and R170 are suitable refrigerants for the low-temperature and medium-temperature cycles. For the high-temperature cycle of the cascade refrigeration system, R717, R152a, and R161 refrigerants were identified as the most suitable options. Overall, the authors recommended the use of a combination of these refrigerants for a three-stage cascade refrigeration system.

Patel et al. [21] conducted a thermo-economic analysis and optimization to evaluate and compare the performance of using $\mathrm{NH}_{3} / \mathrm{CO}_{2}$ and propane (R290)- $\mathrm{CO}_{2}$. The authors evaluated the influence of several design parameters on the performance of the cascade refrigeration cycle. The results showed that the $\mathrm{R} 290-\mathrm{CO}_{2}$ refrigerant pair provided a $5.33 \%$ lower cost rate than the $\mathrm{NH}_{3} / \mathrm{CO}_{2}$ refrigerant pair. Kumar Singh et al. [22] proposed a cascade refrigeration cycle equipped with a flash tank and a flash intercooler and evaluated its performance from energy, exergy, and economic viewpoints. The authors conducted a comparative study of using different natural refrigerants to determine the most suitable pair. It was found that R717-R290 is the most suitable refrigerant pair from both thermodynamic and economic views. For the system with a refrigeration capacity of $500 \mathrm{~kW}$ that used the R717-R290 refrigerant pair, the maximum COP was found to be 1.917, which corresponded to the total annualized cost of $\$ 836,395 \$ / y r$.

Dual-evaporator or dual-temperature refrigeration systems have attracted much attention recently because of the growing need for two different evaporator temperature ranges in the industry. Dual-evaporator refrigeration systems are appealing because they provide two evaporating temperature ranges using only one system, resulting in reduced capital and operating cost by avoiding the construction of two separate systems [23]. A dual-evaporator cascade vapor compression refrigeration system is a promising concept, evaluated and studies in some previous studies such as the studies of Sánchez et al. [24] and Mohammadi et al. [25]. The primary potential benefit of this system is the ability to provide a high COP in low evaporating temperatures, which is not normally achievable by other types of dual-evaporator refrigeration systems, including the dual-temperature absorption refrigeration systems.

As noted, the proper selection of refrigerants is an important research area to maximize the performance of refrigeration systems and minimize their negative environmental impacts. There is no comprehensive study in the literature to explore the use of different refrigerant pairs in a dual-evaporator cascade vapor compression refrigeration system. Therefore, in this study, a thermodynamic and economic analysis is carried out to assess the potential of using several low GWP refrigerant pairs and identify the most suitable pair. The goal of this work is to fulfill the current need of determining the most suitable environmentally friendly refrigerant couple for a dual-evaporator cascade refrigeration system through conducting a comprehensive comparative thermodynamic and economic 
analysis. Overall, 18 refrigerant pairs, including three refrigerants for the low-temperature cycle and six refrigerants for the high-temperature cycle of the cascade cycle, were carefully chosen from the available refrigerants because of their minimal GWP, are examined in this study. A parametric study is performed to evaluate the performance of the cascade refrigeration cycle and the selected refrigerant pairs over a wide range of design and operating parameters. The refrigerant pair that gives the lowest unit production cost of cooling (UPCC) for the cascade refrigeration system is identified as the most suitable refrigeration pair. An optimization process using a particle swarm optimization (PSO) algorithm is performed to minimize the UPCC of the cascade refrigeration system.

\section{System Description}

Figure 1 shows the simplified schematic layout of the dual-evaporator cascade vapor compression refrigeration cycle evaluated in this study. As illustrated by Figure 1, the dual-evaporator cascade cycle consists of a topping cycle or high-temperature (HT) cycle and a bottoming cycle or a low-temperature (LT) cycle. These topping and bottoming cycles are thermally connected through a cascade (Cas) heat exchanger, which plays a role as an evaporator for the HT cycle and as a condenser for the LT cycle.

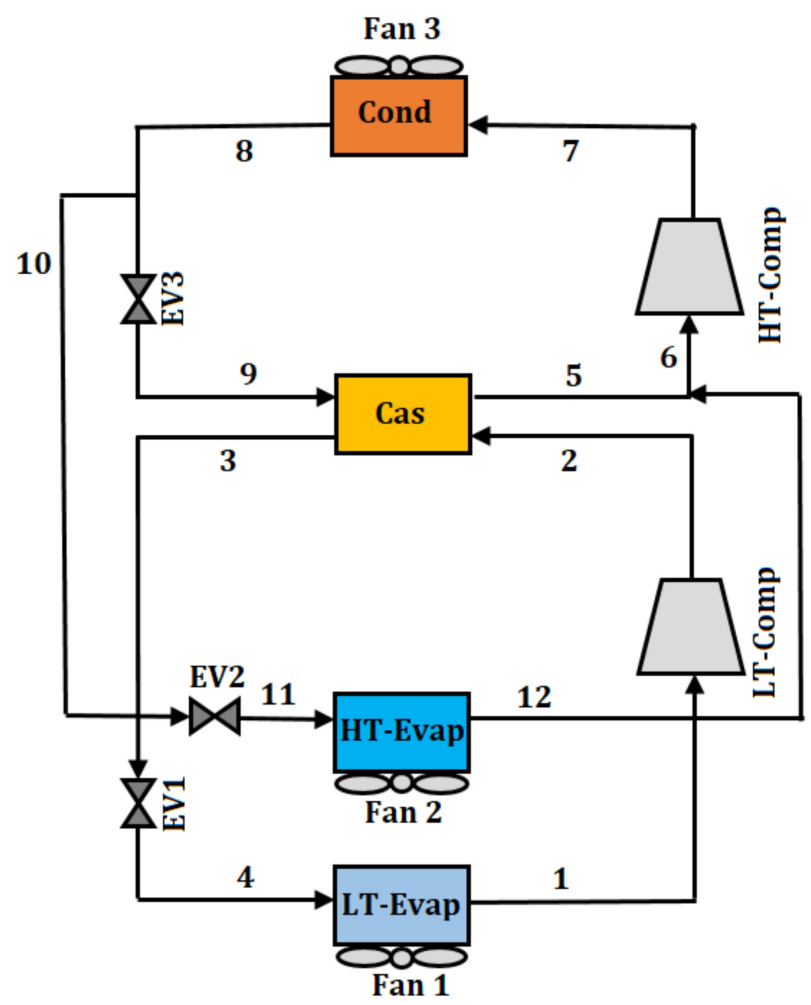

Figure 1. Simplified schematic layout of the dual-evaporator cascade vapor compression refrigeration system.

This cycle is an extension of a traditional cascade refrigeration cycle by adding a second evaporator and an expansion valve that enable generating refrigeration effects at two different temperatures. In the dual-evaporator cycle, a part of the HT refrigerant stream that exits the condenser (state point 8) passes through the expansion valve 2 (EV2), reducing the temperature and pressure of the stream, and then enters the high-temperature evaporator (HT-Evap). The HT refrigerant that enters the HT-Evap absorbs the cooling load from the cold air at a specific inlet temperature. The rest of the HT stream passes through the EV3 and then goes to the cascade heat exchanger (state point 9). The stream exiting the HT-Evap (state point 12) is mixed with the stream exiting the cascade heat exchanger (state point 5) and then enters the HT-Comp (state point 6), where it is compressed to a 
higher temperature and pressure (state point 7). The HT-refrigerant is then condensed in a condenser and its heat is rejected to the environment through a fan (Fan 3) at a specified inlet temperature.

The LT cycle is similar to a simple vapor compression cycle, where the cascade heat exchanger acts as its condenser. The saturated LT-refrigerant exiting the LT-Evap (state point 1 ) is compressed in the LT-Comp (state point 2) and then passes through the cascade heat exchanger, where it rejects its heat to the HT-refrigerant (state point 3 ). The temperature difference between the state points 5 and 3 is defined by $\Delta T_{C a s}$, which is the temperature difference in the cascade heat exchanger. In the next stage of the process, the LT-refrigerant expands in an expansion valve to reduce its temperature and pressure and then enters the LT-Evap (state point 4), where it absorbs the cooling load from the cold air at a specified inlet temperature.

In this dual-evaporator cascade refrigeration cycle, three fans (fans 1, 2, and 3) are employed in total. Fans 1 and 2 are used to transport heat from cold refrigerated space to LT-Evap and HT-Evap, respectively. Fan 3 rejects the heat from the condenser to the environment. Cold air is sucked from the refrigerated spaces using fans 1 and 2 and is sent to the LT-Evap and HT-Evap. Cold air then rejects heat to the refrigerants, cools down, and leaves the LT-Evap and HT-Evap at a lower temperature. Ambient air is sucked by fan 3 and is sent to the condenser. Then ambient air absorbs the heat of the refrigerant and leaves the condenser at a higher temperature.

For a conventional cascade refrigeration cycle, carbon dioxide-ammonia (R744-R717) is a common refrigerant pair that is used. In this study, 18 refrigerant pairs, which include 3 refrigerants for the LT cycle and 6 refrigerants for the HT cycle, are selected to evaluate and compare their potential for the dual-evaporator cascade refrigeration system. Table 1 presents the basic properties of selected refrigerants taken from the Coolprop package and their global warming potential (GWP) values [26]. These refrigerants were selected among several available refrigerants, due to their very low GWP enabling them to all be environmentally friendly refrigerants. Table 1 shows that the examined refrigerants have different physical properties, including the molar mass, critical temperature, and pressure.

Table 1. Properties of refrigerants selected for this study [26].

\begin{tabular}{ccccc}
\hline Refrigerant & Molar Mass (kg/kmol) & Critical Temperature (K) & Critical Pressure (Bar) & GWP \\
\hline LT cycle & & & & 73.77 \\
R744 & 44.01 & 304.13 & 48.72 & 1 \\
R170 & 30.07 & 305.32 & 50.42 & 5.5 \\
R1150 & 28.05 & 282.35 & & \\
HT cycle & & & 113.33 & 0 \\
R717 & 17.03 & 405.4 & 33.82 & $<1$ \\
R1234yf & 114.04 & 367.85 & 36.35 & $<1$ \\
R1234ze & 114.04 & 382.52 & 50.10 & 4 \\
R161 & 48.06 & 375.25 & 45.55 & 1.8 \\
R1270 & 42.08 & 364.21 & 42.51 & 3 \\
R290 & 44.10 & 369.89 & \\
\hline
\end{tabular}

\section{System Modeling}

In this section, the methodology used for the evaluation, comparison and optimization of the dual-evaporator cascade refrigeration cycle is presented. The refrigeration cycle and the potential of selected refrigerants are evaluated using both thermodynamic and economic models. For thermodynamic modeling, the first law of thermodynamics and the principles of mass and energy balances are applied to all components of the cycle. For economic modeling, a detailed model is developed to calculate the unit production cost of cooling (UPCC) of the dual-evaporator cascade refrigeration cycle. The developed model was implemented and solved numerically in MATLAB software and the thermophysical 
properties of refrigerants at different state points were all calculated using the CoolProp package [27].

\subsection{Thermodynamic Analysis}

The thermodynamic model was developed by making the following key assumptions [28,29]:

1. The system is operating under steady-state conditions.

2. The changes in kinetic, potential, and chemical energies of all components are neglected.

3. Refrigerants at the outlet of the evaporators, cascade heat exchanger, and condenser are saturated.

4. An isenthalpic process occurs inside all three expansion valves.

5. Heat losses between the environment and components and pressure drops in the pipelines are neglected.

6. Heat transfer processes in all heat exchangers are isobaric.

Considering the above-mentioned assumptions and a control volume for each component, the following mass and energy balances equations are established. It is important to mention that the numbers that appear in each equation match the state points presented in Figure 1.

LT-Evap:

$$
\begin{gathered}
\dot{m}_{1}=\dot{m}_{4} \\
\dot{Q}_{L T-\text { Evap }}=\dot{m}_{1}\left(h_{1}-h_{4}\right)
\end{gathered}
$$

HT-Evap:

$$
\begin{gathered}
\dot{m}_{11}=\dot{m}_{12} \\
\dot{Q}_{H T-\text { Evap }}=\dot{m}_{11}\left(h_{12}-h_{11}\right)
\end{gathered}
$$

LT-Comp:

$$
\begin{aligned}
& \dot{m}_{1}=\dot{m}_{2} \\
& \dot{W}_{L T-\text { Comp }}=\dot{m}_{1}\left(h_{2, \mathrm{~s}}-h_{1}\right) /\left(\eta_{\text {isen,comp }} \times \eta_{\text {elec }} \times \eta_{\text {mech }}\right)=\dot{m}_{1}\left(h_{2}-h_{1}\right) /\left(\eta_{\text {elec }} \times \eta_{\text {mech }}\right) \\
& \dot{m}_{6}=\dot{m}_{7} \\
& \dot{W}_{H T-\text { Comp }}=\dot{m}_{6}\left(h_{7, \mathrm{~s}}-h_{6}\right) /\left(\eta_{\text {isen, }, \text { comp }} \times \eta_{\text {elec }} \times \eta_{\text {mech }}\right)=\dot{m}_{6}\left(h_{7}-h_{6}\right) /\left(\eta_{\text {elec }} \times \eta_{\text {mech }}\right)
\end{aligned}
$$

Cond:

$$
\begin{gathered}
\dot{m}_{7}=\dot{m}_{8} \\
\dot{Q}_{\text {Cond }}=\dot{m}_{7}\left(h_{7}-h_{8}\right)
\end{gathered}
$$

Cas:

$$
\begin{gathered}
\dot{m}_{2}=\dot{m}_{3} \\
\dot{m}_{5}=\dot{m}_{9} \\
\dot{m}_{6}=\dot{m}_{5}+\dot{m}_{12} \\
\dot{Q}_{C a s}=\dot{m}_{2}\left(h_{2}-h_{3}\right)=\dot{m}_{5}\left(h_{5}-h_{9}\right) \\
\Delta T_{\text {Cas }}=T_{3}-T_{5}
\end{gathered}
$$

Expansion valves (EVs):

$$
\begin{aligned}
\dot{m}_{3} & =\dot{m}_{4} \\
h_{3} & =h_{4} \\
\left(1-x_{m}\right) & \times \dot{m}_{8}=\dot{m}_{9}
\end{aligned}
$$




$$
\begin{gathered}
h_{8}=h_{9} \\
\dot{m}_{10}=\dot{m}_{11} \\
\dot{m}_{10}=x_{m} \times \dot{m}_{8} \\
h_{10}=h_{11}
\end{gathered}
$$

Fans:

$$
\begin{gathered}
\dot{W}_{\text {Fan } 1}=0.075 \times \dot{Q}_{\text {LT-Evap }} \\
\dot{W}_{\text {Fan } 2}=0.075 \times \dot{Q}_{H T-\text { Evap }} \\
\dot{W}_{\text {Fan } 3}=0.027 \times\left(\dot{Q}_{L T-E v a p}+\dot{Q}_{H T-E v a p}+\dot{Q}_{\text {Cond }}\right)
\end{gathered}
$$

$\eta_{\text {isen,comp }}$ is the isentropic efficiency of both LT-Comp and HT-Comp determined as follows [29]:

$$
\eta_{\text {isen }, \text { comp }}=0.9343-0.04478 \times\left(P_{\text {out }} / P_{\text {in }}\right)
$$

$P_{\text {out }}$ and $P_{\text {in }}$ are the pressures at the outlet and inlet of the compressors, respectively. $\eta_{\text {elec }}$ and $\eta_{\text {mech }}$ are the electrical and mechanical efficiencies of the LT-Comp and HT-Comp, which are assumed to be a constant value equal to 0.95 [29].

$\Delta T_{\text {Cas }}$, presented in Equation (14), is the temperature difference in the cascade heat exchanger. The temperature difference of cold air entering and exiting the evaporators is assumed to be $5 \mathrm{~K}$. The temperature difference between the ambient air entering the condenser and the air temperature exiting the condenser is assumed to be $5 \mathrm{~K}$.

The coefficient of performance (COP) is used as a criterion to evaluate the thermodynamic performance of the cascade refrigeration cycle [30,31]:

$$
\mathrm{COP}=\frac{\dot{Q}_{L T-E v a p}+\dot{Q}_{H T-E v a p}}{\dot{W}_{L T-\text { Comp }}+\dot{W}_{H T-C o m p}+\sum_{i=1}^{3} \dot{W}_{F a n, i}}
$$

\begin{tabular}{|c|c|}
\hline Parameter & Value/Unit \\
\hline$\dot{Q}_{L T-E v a p}$ & $200 \mathrm{~kW}$ \\
\hline$\dot{Q}_{H T-E v a p}$ & $500 \mathrm{~kW}$ \\
\hline$T_{L T-E v a p}$ & $233 \mathrm{~K}$ \\
\hline$T_{H T-E v a p}$ & $253 \mathrm{~K}$ \\
\hline$T_{\text {Cond }}$ & $308 \mathrm{~K}$ \\
\hline$T_{\text {Cas }}$ & $273 \mathrm{~K}$ \\
\hline$\Delta T_{\text {Cas }}$ & $5 \mathrm{~K}$ \\
\hline
\end{tabular}

Table 2 presents the main system parameters used for modeling the dual-evaporator cascade refrigeration cycle. $T_{\mathrm{Cas}}$ is the temperature of the low-temperature refrigerant exiting the cascade heat exchanger (state point 3 in Figure 1). As presented by Equation (14), $\Delta T_{C a s}$ is the temperature difference in the cascade heat exchanger (temperature difference between state points 3 and 5 in Figure 1).

Table 2. Main system parameters used for modeling.

\subsection{Economic Analysis}

The unit production cost of cooling (UPCC) was used as an economic criterion to evaluate the potential of using different refrigerants in the dual-evaporator cascade refrigeration cycle and identify the most economical refrigerant pair. UPCC can be calculated in the following general form as presented by Equation (27) [29]:

$$
U P C C=\frac{A C C+A O C}{\left(\dot{Q}_{L T-E v a p}+\dot{Q}_{H T-E v a p}\right) \times \text { operating hours }}
$$


where $A C C$ is annualized capital cost, and $A O C$ is annualized operating cost. In this study, the operating hours are assumed to be $5000 \mathrm{~h}$. ACC is calculated by annualizing the total capital cost of the system using a capital recovery factor (CRF), obtained by Equation (28) as follows:

$$
C R F=\frac{\left(I r(1+I r)^{n}\right)}{(1+I r)^{n}-1}
$$

Ir is the interest rate (0.07) and $n$ is the lifetime of the refrigeration system (20 years).

To calculate the total capital cost of the refrigeration system, the methodology applied by $[32,33]$ is used in this study. The total capital cost consists of three terms of direct cost (DC), indirect cost (IDC), and other outlays cost (OC). Details of the calculation of these three terms can be found in $[32,33]$.

Equipment cost includes the cost of two evaporators, a condenser, a cascade heat exchanger, two compressors, three fans, and three expansion valves. The cost of two evaporators, the condenser, and the cascade heat exchanger is a function of their heat transfer area which is determined based on the logarithmic mean temperature difference (LMTD) method. For each of these components, LMTD is a function of their heat transfer rate, heat transfer area, and overall heat transfer coefficient. For high-temperature evaporator, lowtemperature evaporator, condenser, and cascade heat exchanger, the overall heat transfer coefficient values are assumed to be $0.3 \mathrm{~kW} / \mathrm{m}^{2} \mathrm{~K}, 0.3 \mathrm{~kW} / \mathrm{m}^{2} \mathrm{~K}$, and $0.3 \mathrm{~kW} / \mathrm{m}^{2} \mathrm{~K}$ and $2.5 \mathrm{~kW} / \mathrm{m}^{2} \mathrm{~K}$, respectively. Table 3 presents the equations used to calculate the capital cost of different components of the dual-evaporator cascade refrigeration system.

Table 3. Equations used to calculate the capital cost of components [34,35].

\begin{tabular}{clc}
\hline Components & \multicolumn{1}{c}{ Cost Equations } & Eq. \# \\
\hline Evaporators/condenser & $\log _{10}\left(C_{\text {Cond / Evap }}^{o}\right)=4.0336+0.2341 \log _{10}(A)+0.0497\left[\log _{10}(A)\right]^{2}$ & $(29)$ \\
Cascade heat exchanger & $\log _{10}\left(C_{\text {Cas }}^{o}\right)=4.6656-0.1557 \log _{10}(A)+0.1547\left[\log _{10}(A)\right]^{2}$ & $(30)$ \\
Compressors & $C_{\text {Comp }}=98,400 \times\left(\frac{\dot{W}_{\text {Comp }}}{250}\right)$ & $(31)$ \\
Valves & $C_{\text {Valve }}=114 \times \dot{m}$ \\
Fans & $C_{\text {Fan }}=\left(12400\left(\frac{\dot{W}_{\text {Fan }}}{50}\right)^{0.76}\right)$ \\
\hline
\end{tabular}

$A O C$ includes three terms of the annual maintenance cost, annual insurance cost and annual electricity cost purchased to drive the compressors and fans. The annual maintenance is assumed to be $3 \%$ of total capital cost, and insurance cost is assumed to be $1 \%$ of $C_{e q}$. The specific electricity cost is assumed to be $\$ 0.07 / \mathrm{kWh}$.

\subsection{Economic Optimization Using PSO Algorithm}

In this work, the focus of the optimization is to minimize the UPCC of the refrigeration system and determine which refrigerant pair gives the minimum UPCC. According to the developed thermodynamic and economic model, several parameters such as $\Delta T_{C a s}$, $T_{\text {Cas }}, T_{\text {Cond }}, T_{L T-E v a p}, T_{H T-E v a p}, \dot{Q}_{L T-E v a p}$, and $\dot{Q}_{H T-E v a p}$ influence the performance of the refrigeration system. Selection of $T_{\text {Cond }}$ depends on the weather conditions of the location of interest and selection of $T_{L T-E v a p}, T_{H T-E v a p}, \dot{Q}_{L T-E v a p}$, and $\dot{Q}_{H T-E v a p}$ depends on the desired refrigeration application and the required size for the refrigeration system. Therefore, it may not be reasonable to select $T_{L T-E v a p}, T_{H T-E v a p}, \dot{Q}_{L T-E v a p}$, and $\dot{Q}_{H T-E v a p}$ as decision variables for the optimization purpose and identify the optimum values of these parameters. In this study, $\Delta T_{C a s}$ and $T_{C a s}$ are considered as decision variables, and their ranges are assigned between $3-10 \mathrm{~K}$ and $263-283 \mathrm{~K}$, respectively. 
Although several optimization approaches have been proposed so far, the particle swarm optimization (PSO) algorithm is chosen in this study and implemented in MATLAB to minimize the UPCC and find the optimal values of $\Delta T_{C a s}$ and $T_{C a s}$. PSO is a metaheuristic swarm intelligence inspired by the motion of biological groups behaviors like bird flocking and fish schooling. PSO is based on agents moving through search space to find an optimal solution. Implementation of the PSO algorithm has several benefits such as high precision, strong global search potential, and rapid convergence. PSO has also very few user-defined variables, allowing it to be conveniently implemented for optimization purposes [36] These user-defined variables include the number of iterations and population and learning coefficients, which should be selected carefully to reduce the convergence time and improve the optimization performance [36]. PSO has shown successful application in several areas including science, and engineering optimization problems, function optimization, training of neural networks, and fuzzy system control [37,38]. The PSO algorithm employed for this work has six tuning parameters: the maximum number of iterations (50), the population size (100), two learning coefficients with a value of 2 for each, inertia weight (1), and inertia damping coefficient (0.99) [39].

\subsection{Thermodynamic Model Validation}

The results of this study are compared with those presented by [40] in terms of COP, for a R744-R717 traditional cascade refrigeration cycle. Table 4 presents the validation results for different $T_{\text {Evap }}$ values and for $T_{\text {Cond }}=308 \mathrm{~K}, \Delta T_{C a s}=5 \mathrm{~K}, T_{C a s}=265 \mathrm{~K}$, and $\eta_{\text {isen,comp }}=0.7$. Further validation results are presented in Table 5 for different $T_{\text {Cond }}$ values and for $T_{\text {Evap }}=238 \mathrm{~K}, \Delta T_{\text {Cas }}=5 \mathrm{~K}, T_{\text {Cas }}=265 \mathrm{~K}$, and $\eta_{\text {isen,comp }}=0.7$. These validation results show that the results of this study are in good agreement with those of Messineo [40].

Table 4. Validation results in terms of COP for different $T_{\text {Evap }}$ values.

\begin{tabular}{cccc}
\hline $\boldsymbol{T}_{\text {Evap }}(\boldsymbol{K})$ & This Study & Study of Messineo [40] & Relative Difference (\%) \\
\hline 223 & 1.275 & 1.29 & -1.16 \\
227 & 1.394 & 1.41 & -1.13 \\
232 & 1.523 & 1.54 & -1.10 \\
236 & 1.663 & 1.68 & -1.01 \\
241 & 1.833 & 1.85 & -0.92 \\
245 & 2.003 & 2.02 & -0.84 \\
250 & 2.204 & 2.22 & -0.72 \\
254 & 2.435 & 2.45 & -0.61 \\
259 & 2.685 & 2.70 & -0.56 \\
263 & 2.978 & 2.99 & -0.40 \\
\hline
\end{tabular}

Table 5. Validation results in terms of COP for different $T_{\text {Cond }}$ values.

\begin{tabular}{cccc}
\hline $\boldsymbol{T}_{\text {Cond }}(\boldsymbol{K})$ & This Study & Study of Messineo [40] & Relative Difference (\%) \\
\hline 298 & 2.047 & 2.07 & -1.11 \\
301 & 1.951 & 1.97 & -0.96 \\
304 & 1.863 & 1.88 & -0.90 \\
306 & 1.775 & 1.79 & -0.84 \\
309 & 1.697 & 1.71 & -0.76 \\
312 & 1.628 & 1.64 & -0.73 \\
315 & 1.559 & 1.57 & -0.70 \\
317 & 1.49 & 1.5 & -0.67 \\
320 & 1.429 & 1.44 & -0.76 \\
323 & 1.371 & 1.38 & -0.65 \\
\hline
\end{tabular}




\section{Results and Discussion}

Table 6 presents different thermodynamic and economic results obtained for 18 refrigerant pairs. Note that for the results of Table $6, \Delta T_{C a s}$ and $T_{C a s}$ are equal to $5 \mathrm{~K}$ and $273 \mathrm{~K}$, respectively. The difference between the thermodynamic and economic performance of the examined refrigerant pairs is due to their different thermophysical properties. The highest and lowest values of COP are equal to 1.727 and 1.552 obtained when R170-R161 and R1150R1234yf are used as refrigerant pairs, respectively. The minimum UPCC of $\$ 0.395 /$ ton-hr is obtained for the R170-R161 pair while the maximum UPCC of $\$ 0.419 /$ ton-hr is attained for the R1150-R1234yf pair, indicating that R170-R161 and R1150-R1234yf are the most and least economical refrigerant pairs for the dual-evaporator cascade refrigeration cycle, respectively.

Table 6. Thermodynamic and economic results obtained for different refrigerant pairs.

\begin{tabular}{|c|c|c|c|c|c|c|c|}
\hline $\begin{array}{l}\text { Refrigerant } \\
\text { Pairs }\end{array}$ & COP & AOC (\$) & $\operatorname{ACC}(\$)$ & $\begin{array}{c}\text { UPCC } \\
\text { (\$/ton-hr) }\end{array}$ & $\dot{W}_{L T-\operatorname{Comp}}(k W)$ & $\dot{W}_{H T-\operatorname{Comp}}(k W)$ & $\dot{W}_{\text {fan-Cond }}(k W)$ \\
\hline R744-R717 & 1.702 & 190,778 & 205,513 & 0.398 & 66.6 & 264.3 & 27.8 \\
\hline R170-R717 & 1.715 & 189,570 & 204,947 & 0.396 & 64.2 & 263.8 & 27.8 \\
\hline R1150-R717 & 1.646 & 196,532 & 208,094 & 0.407 & 77.8 & 266.8 & 28.2 \\
\hline R744-R1234yf & 1.603 & 200,531 & 208,383 & 0.411 & 66.6 & 289.2 & 28.5 \\
\hline R170-R1234yf & 1.614 & 199,307 & 207,815 & 0.409 & 64.2 & 288.6 & 28.4 \\
\hline R1150-R1234yf & 1.552 & 206,356 & 210,975 & 0.419 & 77.8 & 291.9 & 28.9 \\
\hline R744-R1234ze & 1.636 & 197,175 & 207,456 & 0.407 & 66.6 & 280.5 & 28.3 \\
\hline R170-R1234ze & 1.647 & 195,956 & 206,889 & 0.405 & 64.2 & 280.0 & 28.2 \\
\hline R1150-R1234ze & 1.583 & 202,978 & 210,046 & 0.415 & 77.8 & 283.2 & 28.6 \\
\hline R744-R161 & 1.715 & 189,699 & 205,314 & 0.397 & 66.6 & 261.4 & 27.8 \\
\hline R170-R161 & 1.727 & 188,491 & 204,748 & 0.395 & 64.2 & 260.9 & 27.7 \\
\hline R1150-R161 & 1.657 & 195,450 & 207,897 & 0.405 & 77.8 & 264.0 & 28.1 \\
\hline R744-R1270 & 1.689 & 192,038 & 205,947 & 0.400 & 66.6 & 267.4 & 27.9 \\
\hline R170-R1270 & 1.701 & 190,826 & 205,381 & 0.398 & 64.2 & 266.9 & 27.8 \\
\hline R1150- R1270 & 1.633 & 197,806 & 208,532 & 0.408 & 77.8 & 270.0 & 28.3 \\
\hline R744-R290 & 1.684 & 192,518 & 206,079 & 0.401 & 66.6 & 268.7 & 28.0 \\
\hline R170-R290 & 1.696 & 191,307 & 205,512 & 0.399 & 64.2 & 268.1 & 27.9 \\
\hline R1150-R290 & 1.628 & 198,288 & 208,664 & 0.409 & 77.8 & 271.3 & 28.3 \\
\hline
\end{tabular}

The results of Table 6 show that with a proper selection of the refrigerant pair, a thermodynamic and economic performance improvement can be obtained over the R744R717 pair, used as a typical refrigerant pair of cascade refrigeration cycles. The minimum values of AOC, ACC, $\dot{W}_{L T-C o m p}, \dot{W}_{H T-C o m p}$, and $\dot{W}_{\text {fan-Cond }}$ correspond to the R170-R161 pair, which are equal to $\$ 188,491, \$ 204,748,64.2 \mathrm{~kW}, 260.9 \mathrm{~kW}$, and $27.7 \mathrm{~kW}$, respectively. The maximum values of AOC, ACC, $\dot{W}_{L T-C o m p}, \dot{W}_{H T-C o m p}$ and $\dot{W}_{\text {fan-Cond }}$ are obtained for R1150-R1234yf pair which are equal to $\$ 206,356, \$ 210,975,77.8 \mathrm{~kW}, 291.9 \mathrm{~kW}$, and $28.9 \mathrm{~kW}$, respectively. The results of this study support those of previous studies indicating that there are better alternative refrigerant pairs than conventional R744-R717 pair, used in most cascade refrigeration systems. For example, Sun et al. [19] showed that using R41/R161 pair offered the best performance for a conventional cascade refrigeration system. Patel et al. [21] demonstrated that using an R744-R290 pair provided over 5\% lower cost rate than using R744-R717 pair for a conventional cascade refrigeration cycle. Singh et al. [22] found that, for a single evaporator cascade refrigeration cycle that has a flash intercooler in the lower temperature cycle, using an R290-R717 pair offered better thermodynamic and economic performance than using an R744-R717 pair.

The temperature difference in the cascade heat exchanger $\left(\Delta T_{C a s}\right)$, which is the temperature difference between the state points 3 and 5 presented in Figure 1, has a significant influence on the performance of the refrigeration system. Figure 2 shows the effect of $\Delta T_{C a s}$ on the COP of the refrigeration system for different refrigerant pairs. The results demonstrate that with an increase in $\Delta T_{C a s}$ from 3 to $10 \mathrm{~K}$, the COP decreases significantly 
for all refrigerant pairs. It is observed that all refrigerant pairs have almost the same trend of reduction with an increase in $\Delta T_{\text {Cas }}$. The reason for a reduction in the COP is that with an increase $\Delta T_{C a s}$, the temperature gap between state points 3 and 5 increases, which causes a reduction in the temperature of state point 5 because the temperature of state point 3 ( $\left.T_{C a s}\right)$ is constant. This leads to increasing the $\dot{W}_{H T-\text { Comp }}$ and as a result, decreasing the COP for all. Among all selected refrigerant pairs, the highest values of COP are obtained for the R170-R161 pair, while the lowest values are obtained when the R1150-R1234yf pair is used as a refrigerant pair. Compared to R744-R717 as a typical refrigerant pair for cascade vapor compression refrigeration systems which its COP ranges between 1.598 and 1.740, R170-R161 shows slightly higher COP ranging between 1.639 and 1.760 .
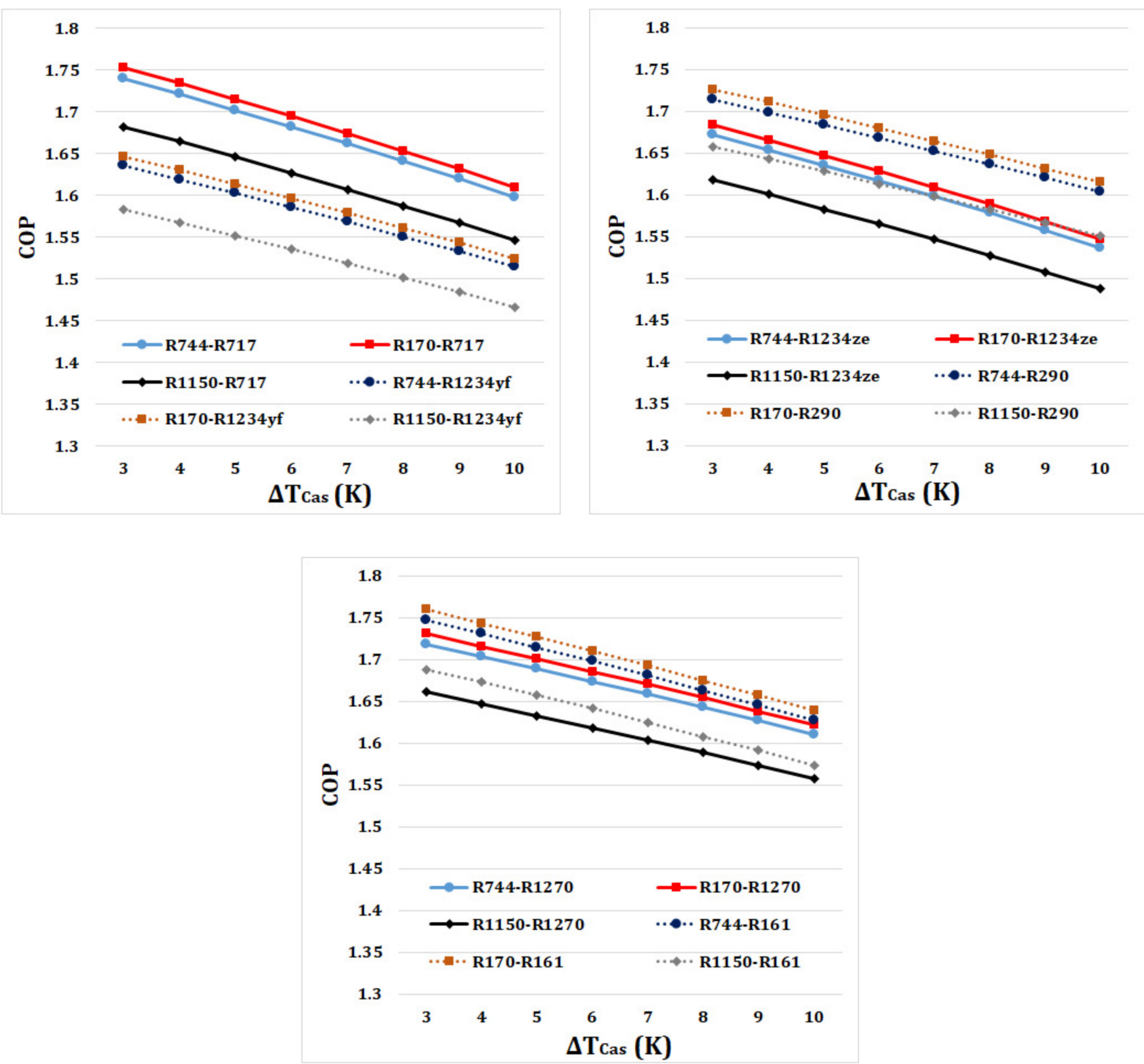

Figure 2. Effect of temperature difference in the cascade heat exchanger $\left(\Delta T_{\text {Cas }}\right)$ on the COP for different refrigerant pairs. 
The influence of $\Delta T_{C a s}$ on the UPCC of the refrigeration system for different refrigerant pairs is shown in Figure 3. It is noted that for all refrigerant pairs, the UPCC slightly decreases first and then increases with a further increase in $\Delta T_{\text {Cas }}$. As noted, with an increase in $\Delta T_{\text {Cas }}$, the COP decreases which causes an increase in the AOC of the system mostly because of an increase in $\dot{W}_{H T-C o m p}$. On the other hand, with an increase in $\Delta T_{C a s}$, the ACC decreases. The increase in the AOC and the decrease in the ACC along with an increase in $\dot{W}_{H T-C o m p}$ causes that the UPCC decreases first and then increases. The minimum UPCC is obtained when $\Delta T_{C a s}$ is close to either $4 \mathrm{~K}$ or $5 \mathrm{~K}$. The presented results in Figure 3 clearly show how changing the refrigerant pairs affects the economic performance of the system demonstrating the importance of the proper selection of a refrigerant pair on the economics of the refrigeration system. The lowest values of UPCC, ranging between $\$ 0.397 /$ ton-hr and $\$ 0.401 /$ ton-hr, are obtained when R170-R161 is used as a refrigerant pair while the highest UPCC values, ranging between $\$ 0.421 /$ ton-hr and $\$ 0.427$ /ton-hr, are attained for R1150-R1234yf. For R744-R717 as a typical refrigerant pair of cascade refrigeration cycles, the UPCC values are between $\$ 0.399 /$ ton-hr and $\$ 0.407 /$ ton-hr which are slightly higher than those of R170-R161 as the most economical refrigerant pair.
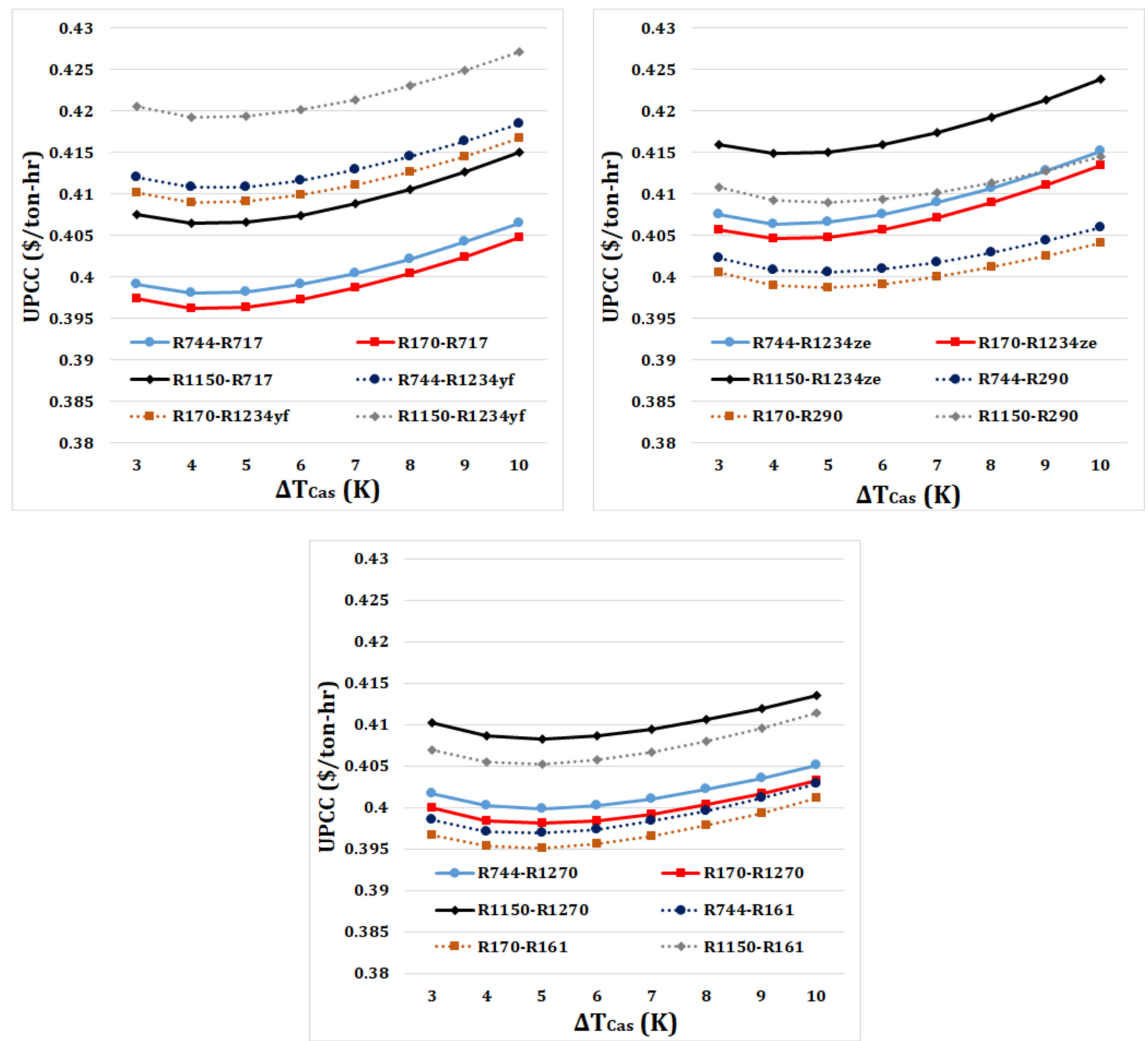

Figure 3. Effect of temperature difference in the cascade heat exchanger $\left(\Delta T_{\text {Cas }}\right)$ on the UPCC for different refrigerant pairs. 
As noted earlier, $T_{C a s}$ is the temperature of the low-temperature refrigerant exiting the cascade heat exchanger (state point 3 in Figure 1). $T_{C a s}$ is another influential parameter on the thermodynamic and economic performance of a dual-evaporator cascade vapor compression refrigeration system.

Figure 4 shows the impact of $T_{C a s}$ on the COP for different refrigerant pairs. It is observed that for all refrigerant pairs, with an increase in $T_{\text {Cas }}$ from $263 \mathrm{~K}$ to $283 \mathrm{~K}$, the COP initially increases and then decreases. These trends of increased and decreased COP with a change in $T_{\mathrm{Cas}}$ are different among the examined refrigerant pairs, because of their different thermophysical properties. With an increase in $T_{C a s}$, the temperature gap between LT-Evap and the cascade heat exchanger (or the condenser of the LT cycle) increases, leading to a rise in $\dot{W}_{L T-C o m p}$. The increase in $T_{C a s}$ causes an increase in the temperature of state point 5 , because of the constant value of $\Delta T_{C a s}$, resulting in a reduction in $\dot{W}_{H T-C o m p}$. For lower values $T_{\text {Cas }}$ values, the decrease in $\dot{W}_{H T \text {-Comp }}$ suppresses the increase in $\dot{W}_{L T-C o m p}$, leading to an increase in the COP while for higher values $T_{\mathrm{Cas}}$ values, the opposite condition happens resulting in a decrease in the COP.
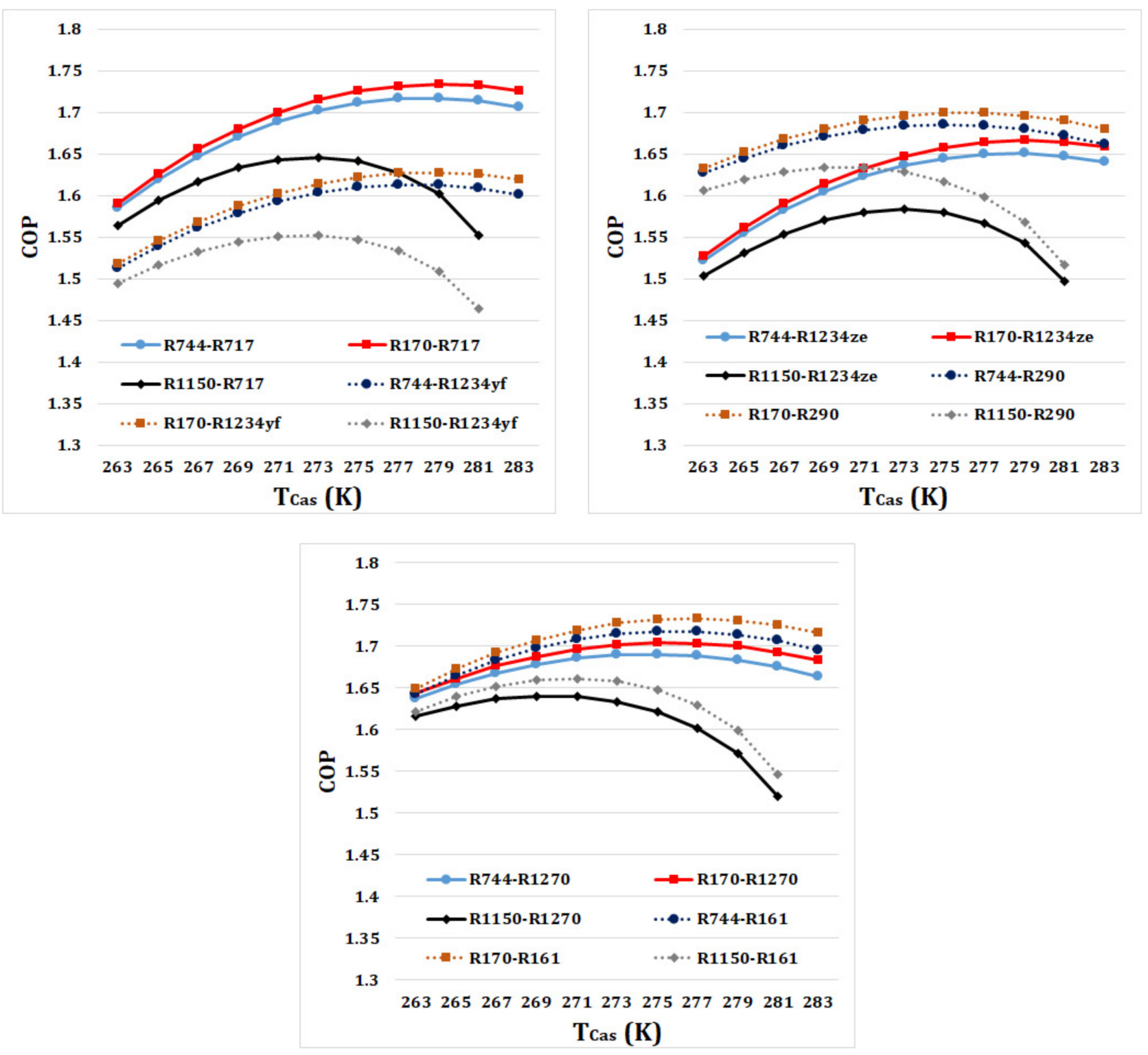

Figure 4. Effect of temperature of the cascade heat exchanger $\left(T_{C a s}\right)$ on the COP for different refrigerant pairs. 
The variation of $T_{\text {Cas }}$ with UPCC for different refrigerant pairs is shown in Figure 5. It is observed that UPCC has a decreasing and increasing pattern with a variation in $T_{C a s}$. As shown, the trends of these decreases and increases are different for each refrigerant pair, due to their different thermophysical properties. For each refrigerant pair, the minimum UPCC is obtained at a specific value of $T_{C a s}$, indicating that the same $T_{C a s}$ cannot be used for all refrigerant pairs. For all values of $T_{C a s}$, the minimum UPCC is obtained when R170-R161 is used as a refrigerant pair. As shown in Figure 4, when $T_{C a s}$ increases, COP has an increasing and decreasing trend. This results in an opposite trend of variation (a decreasing and increasing trend) in the AOC of the refrigeration cycle. While the ACC of the refrigeration system increases with an increase in $T_{C a s}$. These different trends of variation in the AOC and ACC cause a decreasing and increasing pattern of variation in the UPCC with an increase in $T_{\text {Cas }}$.
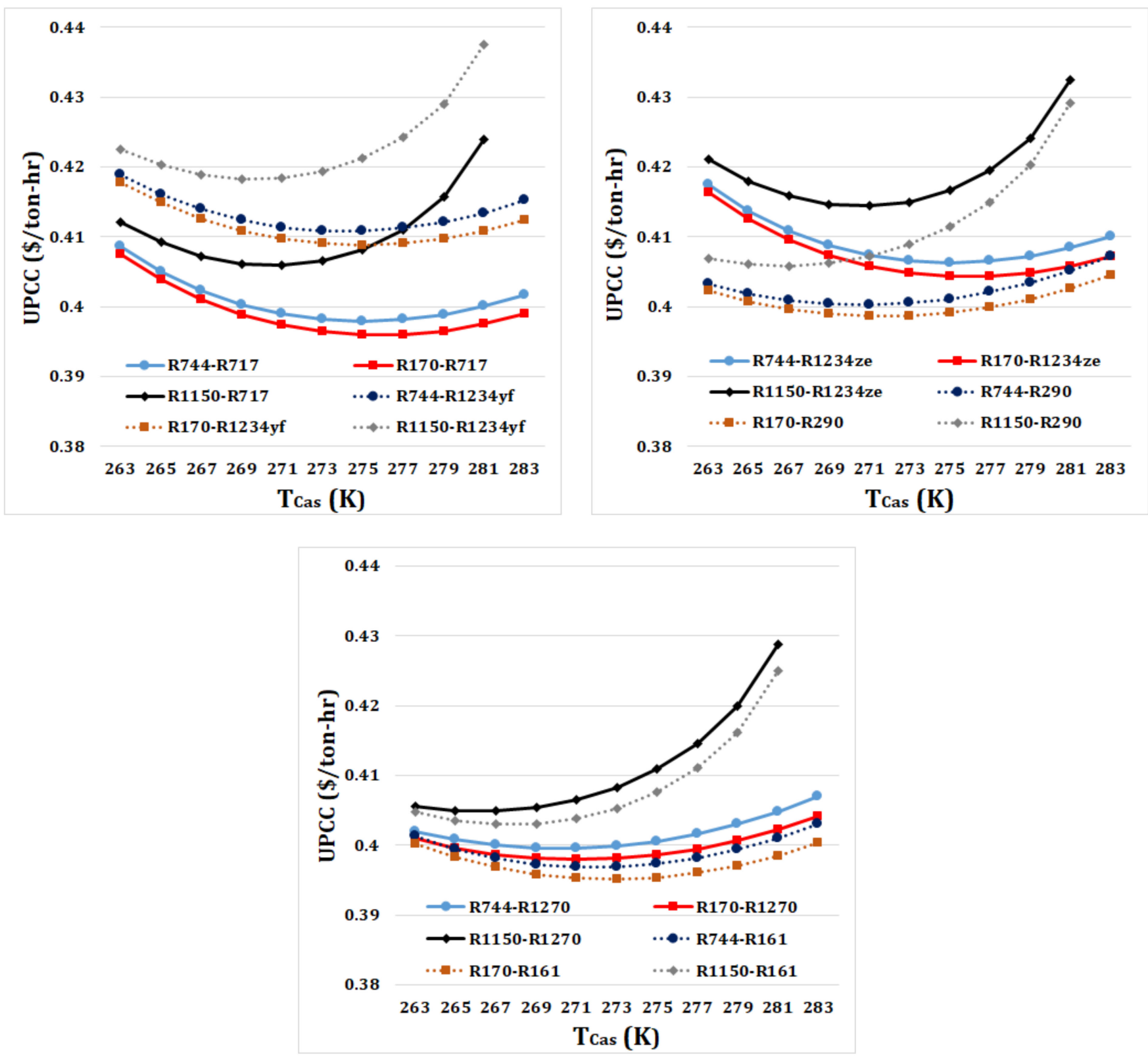

Figure 5. Effect of temperature of the cascade heat exchanger $\left(T_{C a s}\right)$ on the UPCC for different refrigerant pairs. 
For the previous analyses, the values of $T_{L T-E v a p}$ and $T_{H T-E v a p}$ were fixed at $233 \mathrm{~K}$ and $253 \mathrm{~K}$, respectively. Depending on the application, different values of $T_{L T-E v a p}$ and $T_{H T-E v a p}$ can be set for a dual-evaporator cascade refrigeration cycle. Figures 6-9 show the influence of a change in either $T_{L T-E v a p}$ or $T_{H T-E v a p}$ on the COP and UPCC of the cascade refrigeration cycle. For these analyses, $\Delta T_{C a s}$ and $T_{C a s}$ are set fixed at $5 \mathrm{~K}$ and $273 \mathrm{~K}$, respectively. In addition, when $T_{L T-E v a p}$ is varied, $T_{H T-E v a p}$ is set at $253 \mathrm{~K}$ and when $T_{H T-E v a p}$ is varied, $T_{L T-E v a p}$ is set at $233 \mathrm{~K}$. According to Figures 6 and 8, COP increases with an increase in either $T_{L T-E v a p}$ and $T_{H T-E v a p}$. This happens because an increase in the evaporator temperatures decreases the temperature gap between the LT and HT cycles resulting in a decrease in $\dot{W}_{L T-C o m p}$ and $\dot{W}_{H T-C o m p}$ and as a result an increase in the cycle's COP.
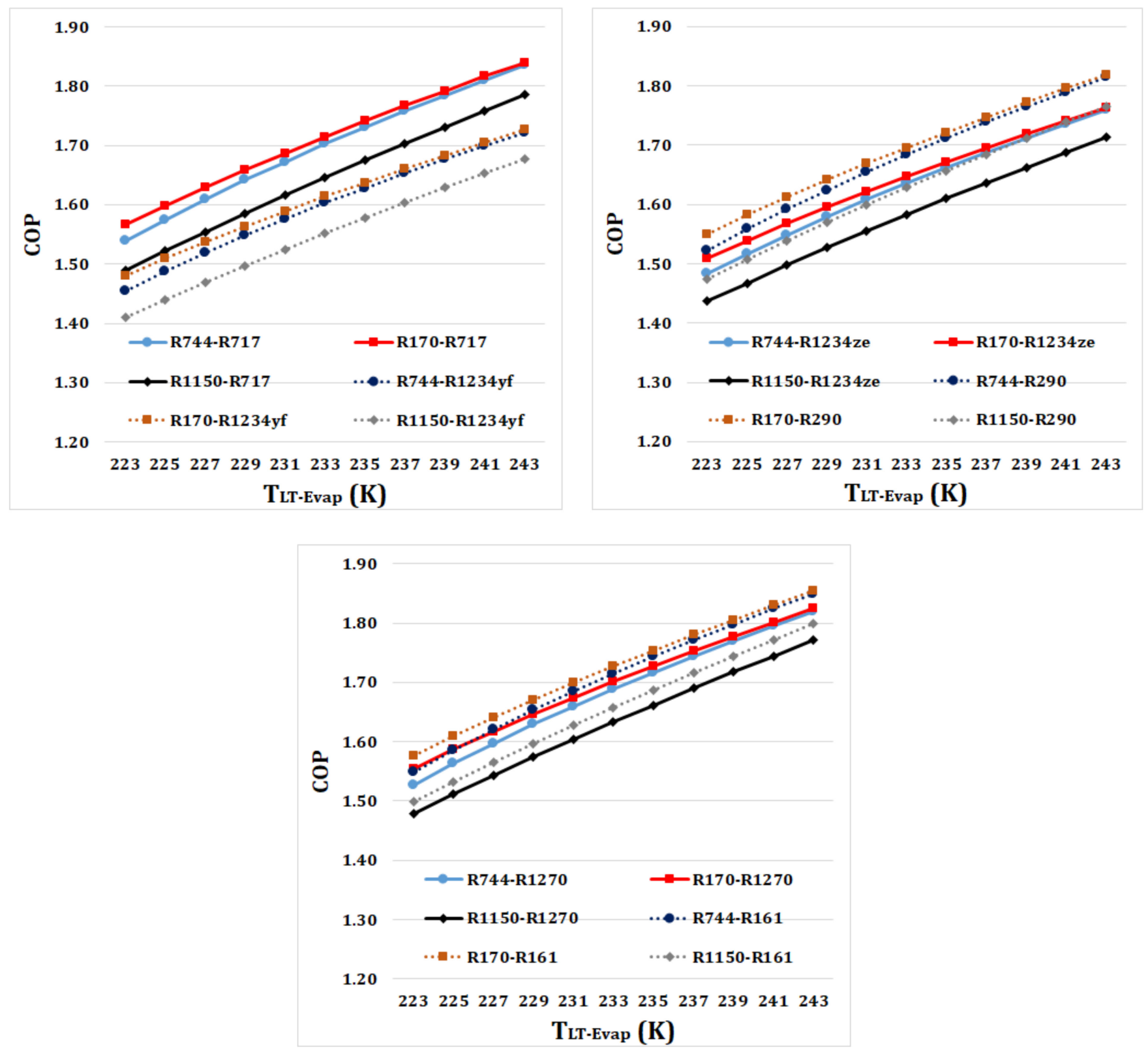

Figure 6. Effect of low-temperature evaporator $\left(T_{L T-E v a p}\right)$ on the COP for different refrigerant pairs. 
The highest COP values for all $T_{L T-E v a p}$ and $T_{H T-E v a p}$ values are obtained for the R170-R161 refrigerant pair. While the lowest COP values are obtained when R1150-R1234yf is used as a refrigerant pair. According to Figures 6 and 8, using R170-R161 as a refrigerant pair, the COP increases from 1.577 to 1.855 with an increase in $T_{L T \text {-Evap }}$ from $223 \mathrm{~K}$ to $243 \mathrm{~K}$ and increases from 1.514 to 1.965 with an increase in $T_{H T-E v a p}$ from $243 \mathrm{~K}$ to $263 \mathrm{~K}$, respectively. While for R744-R717 as a typical refrigerant pair, COP increases from 1.539 to 1.835 and from 1.493 to 1.936, respectively. This shows an advantage of R170-R161 over R744-R717 for all examined ranges of $T_{L T-E v a p}$ or $T_{H T-E v a p}$.
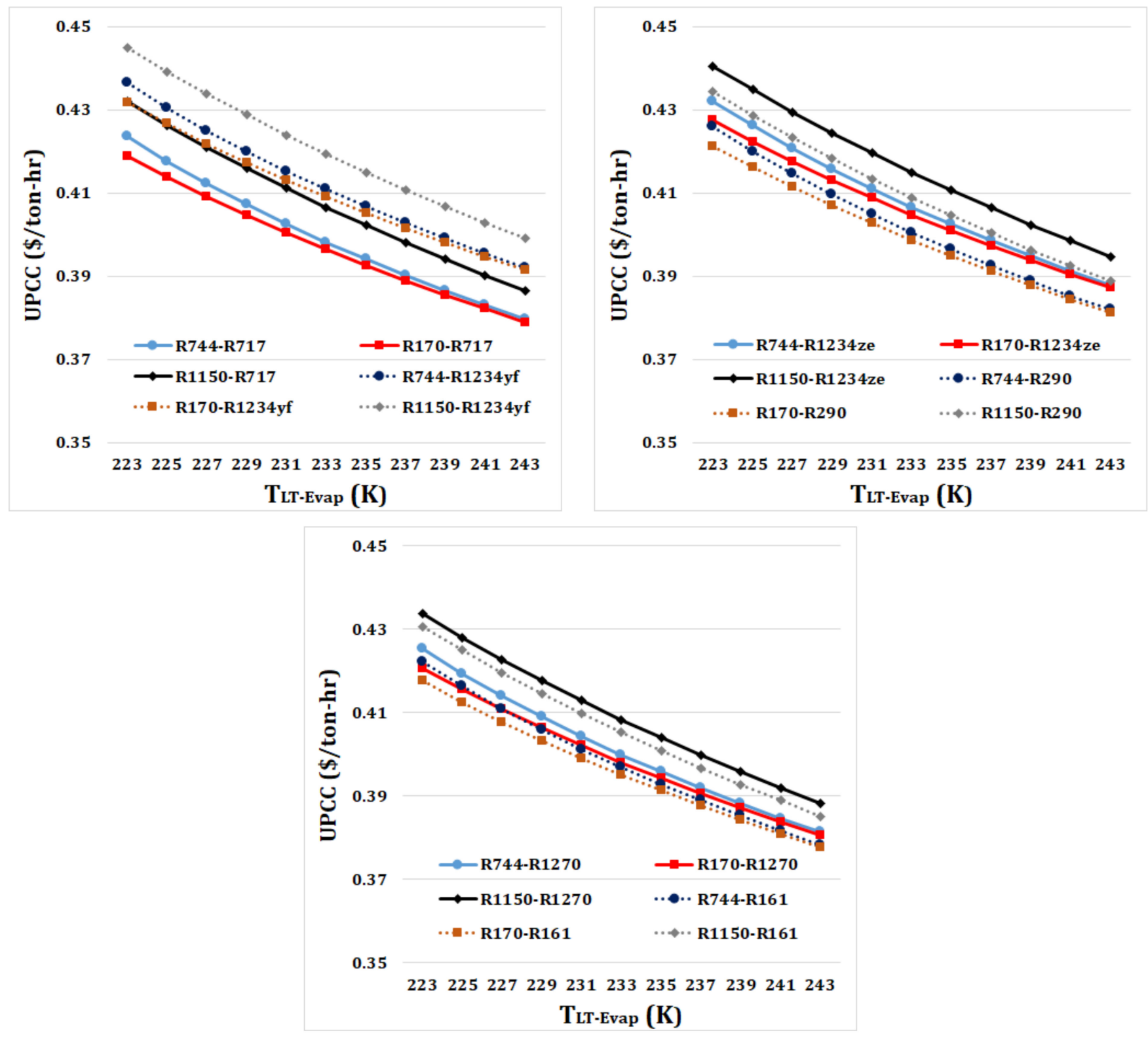

Figure 7. Effect of low-temperature evaporator $\left(T_{L T-E v a p}\right)$ on the UPCC for different refrigerant pairs.

As shown in Figures 7 and 9, the UPCC has a decreasing trend with an increase in both $T_{L T-E v a p}$ and $T_{H T-E v a p}$. It is observed that the decreasing trend of UPCC is almost the same for all refrigerant pairs. With an increase in $T_{L T-E v a p}$ and $T_{H T-E v a p}$, the AOC of the refrigeration cycle decreases mostly because of an increase in the COP. Also, the ACC decreases because of a decrease in the size of components, especially the compressors. The decrease of both AOC and ACC causes a reduction in the UPCC of the cascade refrigeration cycle. According to Figures 7 and 9, the lowest values of UPCC are obtained when R170- 
R161 is used as a refrigerant, followed by R170-R717. R744-R717, as a typical refrigerant pair of cascade refrigeration cycles, is placed as the fourth-best refrigerant pair. With a variation of $T_{L T-E v a p}$ from $223 \mathrm{~K}$ to $243 \mathrm{~K}$, the UPCC for the refrigerant pairs of R170$\mathrm{R} 161$, and R170-R717 varies from $\$ 0.418 /$ ton-hr to $\$ 0.378 /$ ton-hr, and from $\$ 0.419 /$ ton-hr to $\$ 0.379 /$ ton-hr, respectively. When $T_{H T-E v a p}$ from $243 \mathrm{~K}$ to $263 \mathrm{~K}$, the UPCC for the refrigerant pairs of R170-R161, and R170-R717 reduces from $\$ 0.422 /$ ton-hr to $\$ 0.371 /$ ton-h, and from $\$ 0.424 /$ ton-hr to $\$ 0.372 /$ ton-hr, respectively.
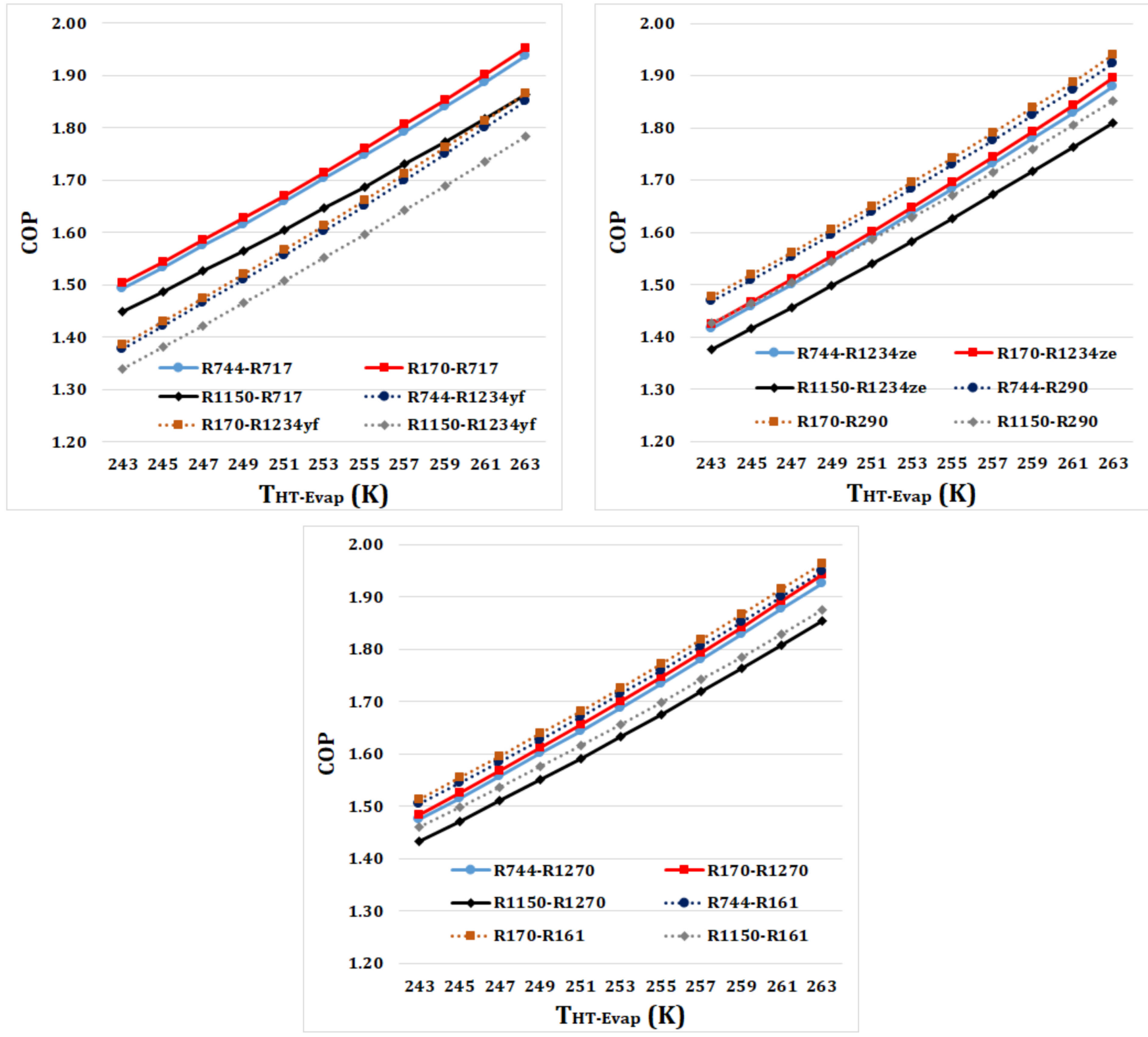

Figure 8. Effect of high-temperature evaporator $\left(T_{H T-E v a p}\right)$ on the COP for different refrigerant pairs. 

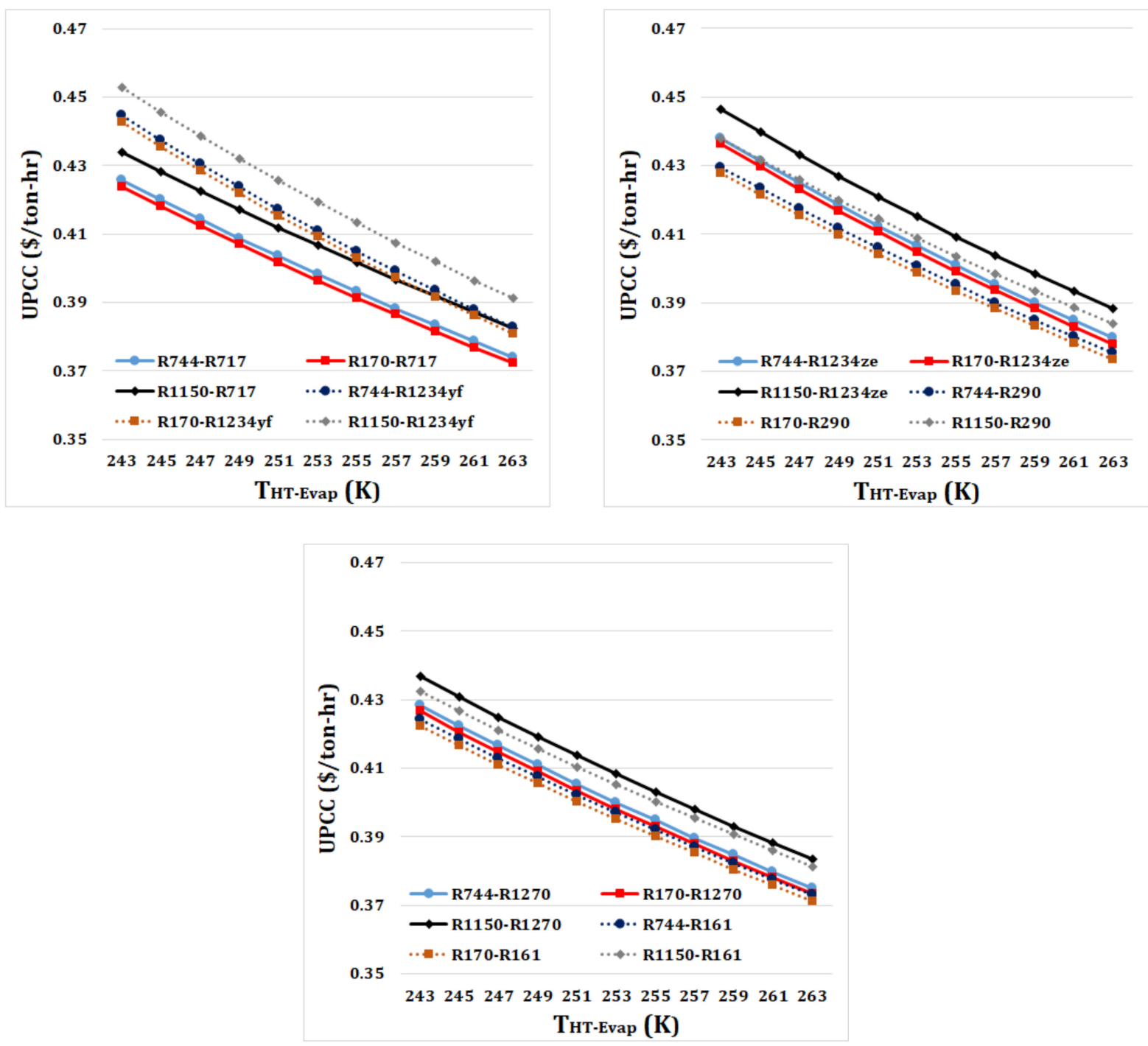

Figure 9. Effect of high-temperature evaporator $\left(T_{H T-E v a p}\right)$ on the UPCC for different refrigerant pairs.

\section{Optimization Results for R170-R161 Refrigerant Pair}

As noted, in this study, a decision was made to optimize the dual-evaporator refrigeration cycle by minimizing the UPCC. The results presented in the previous section demonstrated that, under all parametric study conditions, R170-R161 is the most suitable refrigerant pair from both thermodynamic and economic viewpoints. Thus, the optimization is only conducted for the R170-R161 refrigerant pair. The optimum decision variables of $\Delta T_{C a s}$ and $T_{C a s}$ were obtained as 4.652 and 272.46 , respectively, for the R170-R161 refrigerant pair. It is noticed that these values are very close to the values ( $5 \mathrm{~K}$ and $273 \mathrm{~K}$ ) selected as default values for $\Delta T_{C a s}$ and $T_{C a s}$ in the above analyses. Table 7 presents the optimum values of the main thermodynamic and economic results obtained for the cascade cycle that uses R170-R161 as a refrigerant pair. It is found that optimizing the cycle gives slightly higher COP and lower UPCC values compared to the values presented in Table 7. After the optimization, the values of AOC and ACC slightly decrease. 
Table 7. Thermodynamic and economic results for the optimized cycle using R170-R161 refrigerant pair.

\begin{tabular}{ccccccccc}
\hline COP & AOC (\$) & ACC (\$) & $\begin{array}{c}\text { UPCC } \\
\text { (\$/ton-hr) }\end{array}$ & $\dot{W}_{L T-C o m p}(k W)$ & $\dot{W}_{H T-C o m p}(k W)$ & $\dot{W}_{f a n-L T-E v a p}(k W)$ & $\dot{W}_{\text {fan-HT-Evap }}(k W)$ & $\dot{W}_{f a n-C o n d}(k W)$ \\
\hline 1.731 & 188,143 & 203,952 & 0.394 & 261.3 & 62.9 & 15 & 37.5 & 27.7 \\
\hline
\end{tabular}

The rest of the results from here deals with studying the influence of different important parameters on the performance of an optimized cascade refrigeration cycle that uses the R170-R161 pair. For each analysis, two decision variables of $\Delta T_{C a s}$ and $T_{C a s}$ are optimized for each specific value of the parameters that are varied. The results of these parametric studies are presented in Figures 10-14 and discussed in the following.

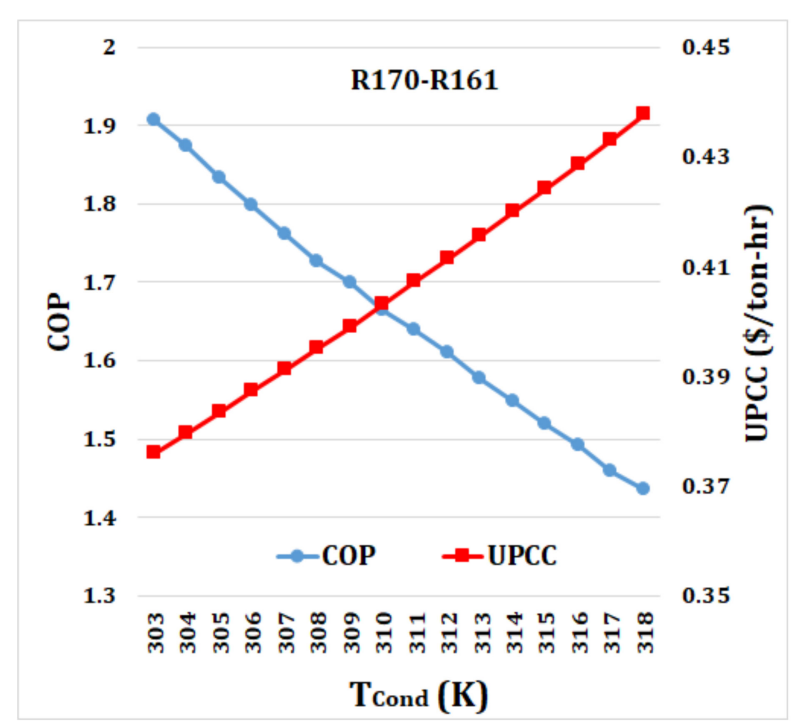

(a)

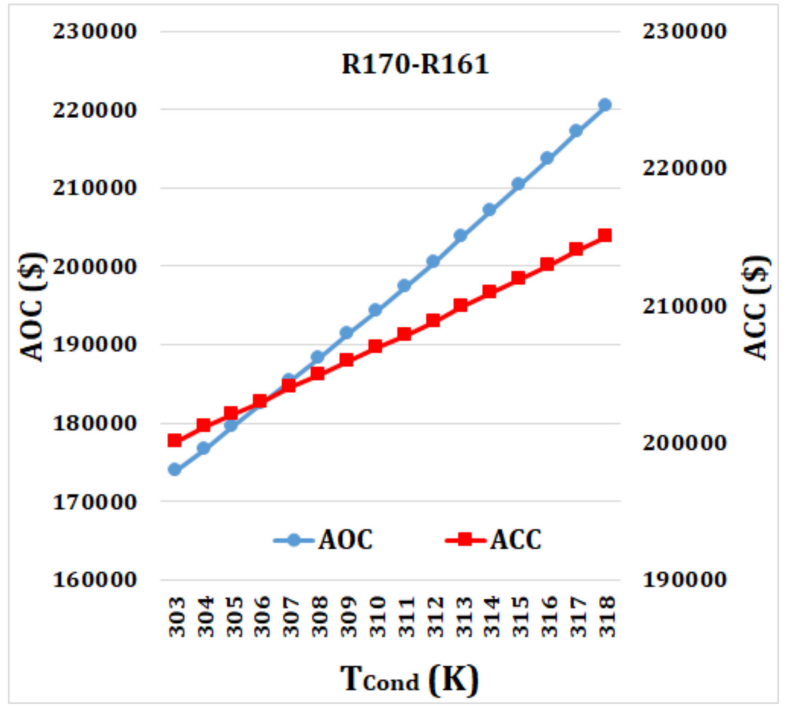

(b)

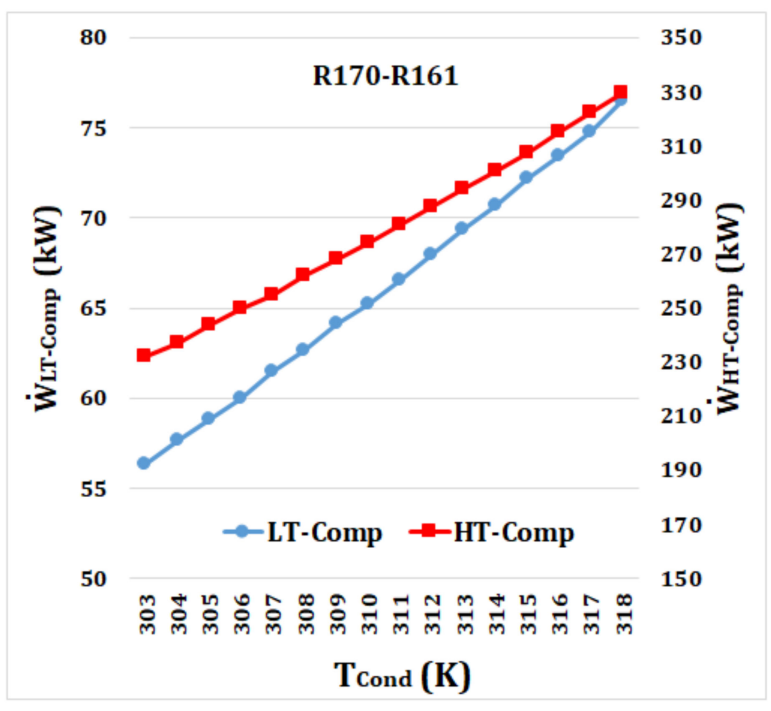

(c)

Figure 10. Effect of $T_{\text {Cond }}$ on (a) COP and UPCC, (b) AOC and ACC, and (c) $\dot{W}_{L T-C o m p}$ and $\dot{W}_{H T-C o m p}$ of the optimized cycle using R170-R161 refrigerant pair. 


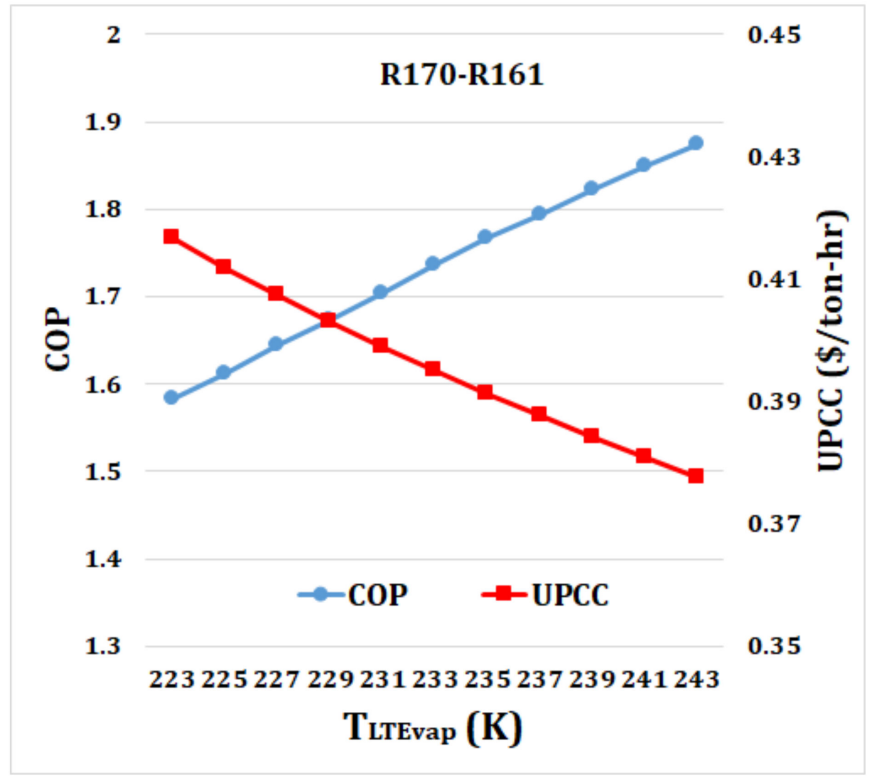

(a)

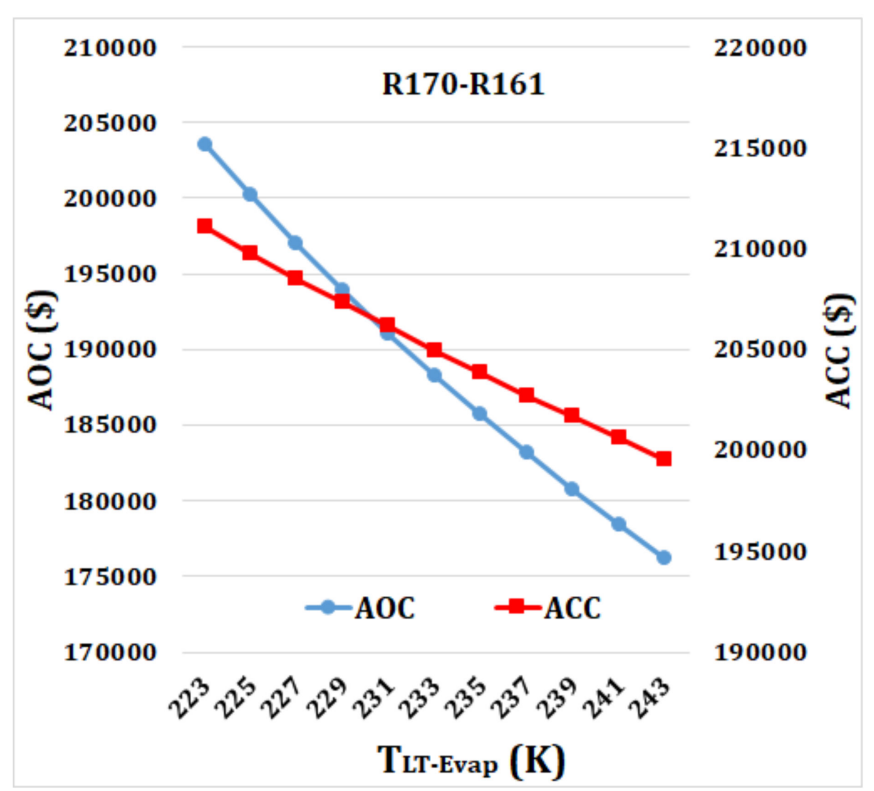

(b)

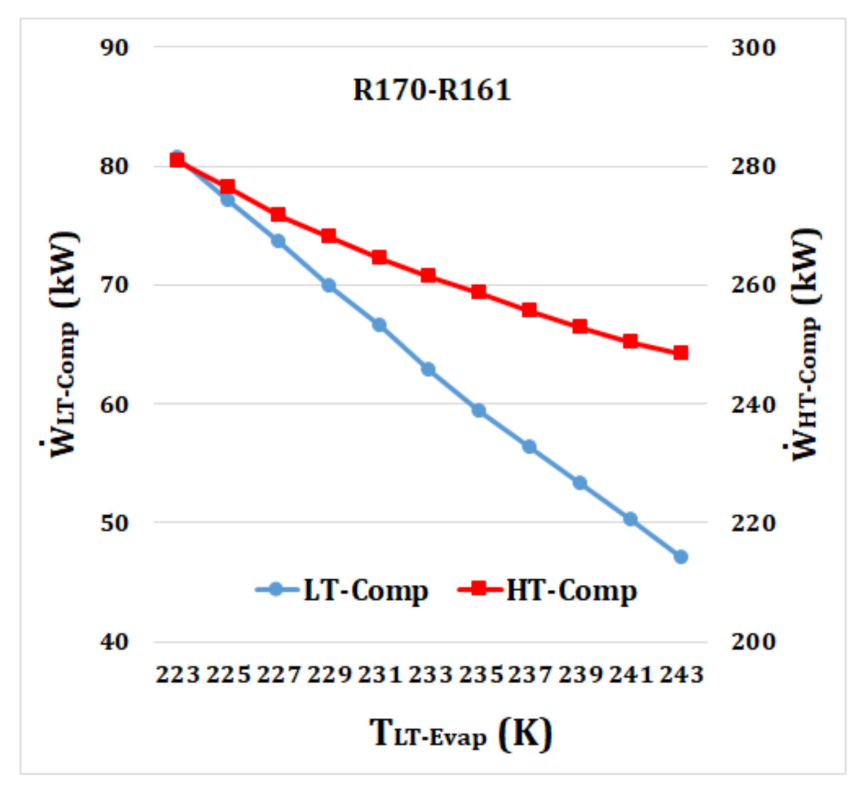

(c)

Figure 11. Effect of $T_{L T-E v a p}$ on (a) COP and UPCC, (b) AOC and ACC, and (c) $\dot{W}_{L T-C o m p}$ and $\dot{W}_{H T-C o m p}$ of the optimized cycle using R170-R161 refrigerant pair.

Figure 10 presents the effect of $T_{\text {Cond }}$ on several thermodynamic and economic parameters of the optimized cycle using R170-R161 as a refrigerant pair. With an increase in $T_{\text {Cond }}$ from $303 \mathrm{~K}$ to $318 \mathrm{~K}$, the optimum values of $\Delta T_{C a s}$ and $T_{C a s}$ vary from $4.83 \mathrm{~K}$ to $4.34 \mathrm{~K}$ and from $269.7 \mathrm{~K}$ to $277.5 \mathrm{~K}$, respectively. According to Figure $10 \mathrm{a}$, an increase in $T_{\text {Cond }}$ causes a decrease in COP, and an increase in UPCC. When $T_{\text {Cond }}$ increases from $303 \mathrm{~K}$ to $318 \mathrm{~K}$, COP decreases significantly from 1.903 to 1.436 and UPCC increases substantially from $\$ 0.376 /$ ton-hr to $\$ 0.438 /$ ton-hr. Figure 10b shows that both AOC and ACC increase with an increase in $T_{\text {Cond }}$. AOC increases from $\$ 173,980$ to $\$ 220,491$ and ACC increases from $\$ 200,106$ to $\$ 215,055$ when $T_{\text {Cond }}$ increases from $303 \mathrm{~K}$ to $318 \mathrm{~K}$. As shown in Figure 10c, both $\dot{W}_{L T-C o m p}$ and $\dot{W}_{H T-C o m p}$ increase significantly from $56.4 \mathrm{~kW}$ to $76.5 \mathrm{~kW}$ and from $232.1 \mathrm{~kW}$ to $329.3 \mathrm{~kW}$, respectively. With an increase of $T_{\text {Cond }}$, the power requirement of the 
compressor, especially the high-temperature compressor increases leading to a decrease in the COP and an increase in the AOC. Also, when $T_{\text {Cond }}$ increases, the ACC increases because of the increase in the size of the condenser and both compressors. The increase in both AOC and ACC causes a significant increase in the UPCC of the cascade refrigeration system.

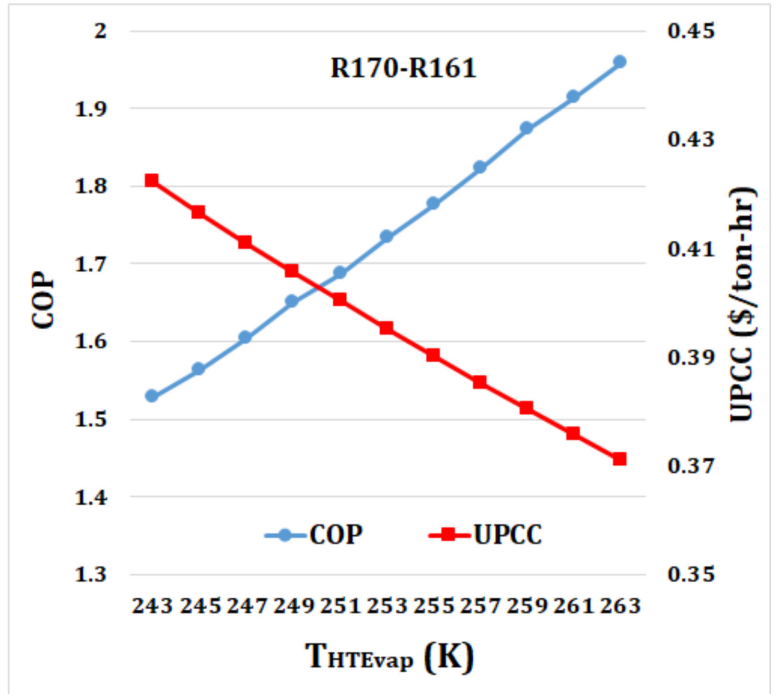

(a)

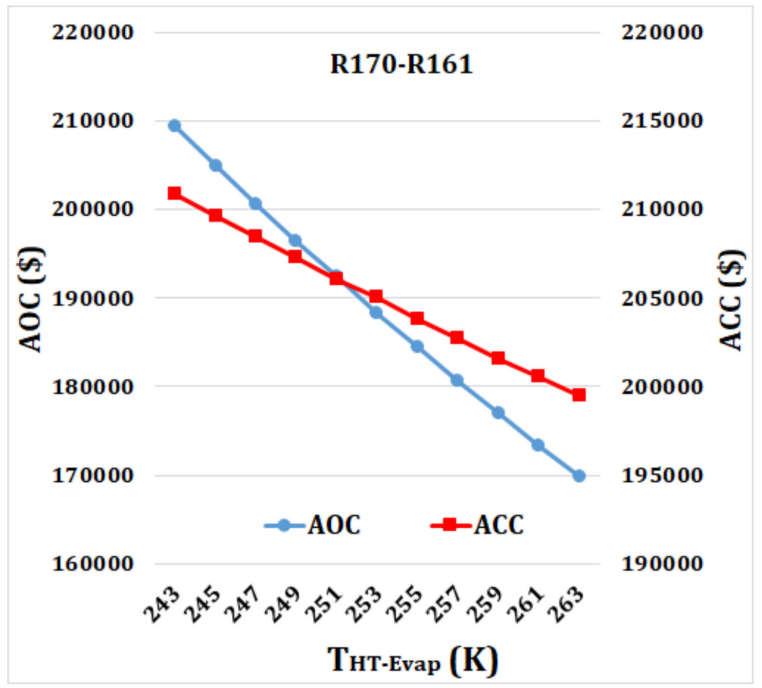

(b)

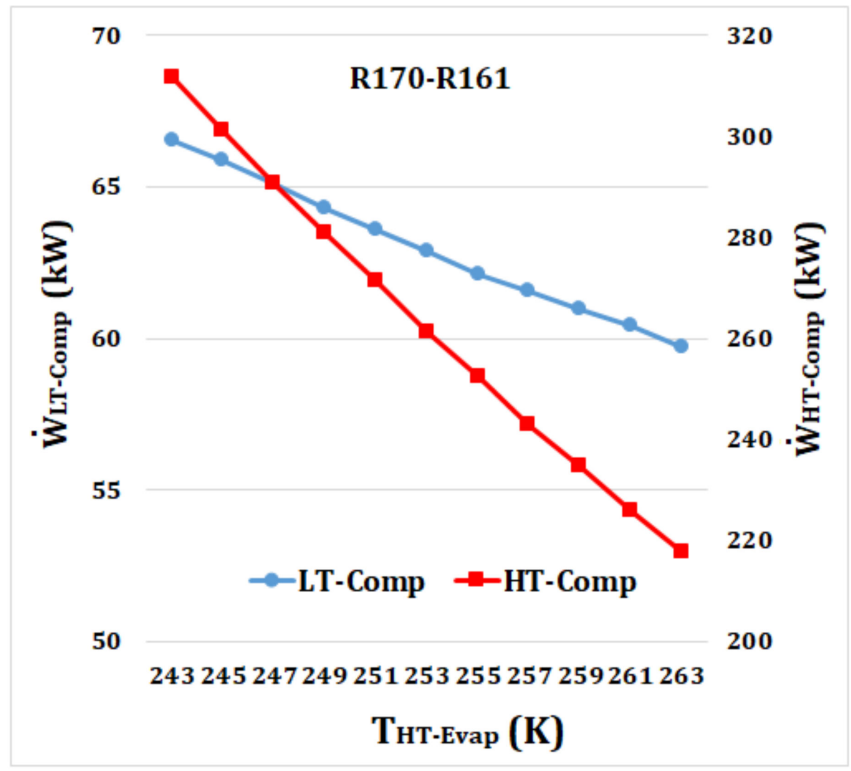

(c)

Figure 12. Effect of $T_{H T-E v a p}$ on (a) COP and UPCC, (b) AOC and ACC, and (c) $\dot{W}_{L T-C o m p}$ and $\dot{W}_{H T-C o m p}$ of the optimized cycle using R170-R161 refrigerant pair.

The influence of $T_{L T-E v a p}$ on different thermodynamic and economic parameters of the optimized cycle using R170-R161 as a refrigerant pair is shown in Figure 11. With an increase in $T_{L T-E v a p}$ from $223 \mathrm{~K}$ to $243 \mathrm{~K}$, the optimum values of $\Delta T_{C a s}$ and $T_{C a s}$ change between $4.38 \mathrm{~K}$ and $4.91 \mathrm{~K}$ and between $268.6 \mathrm{~K}$ to $275.41 \mathrm{~K}$, respectively. As shown in Figure $11 \mathrm{a}$, with an increase in $T_{L T-E v a p}$ from $223 \mathrm{~K}$ to $243 \mathrm{~K}$, COP increases from 1.584 to 1.875 while UPCC decreases from $\$ 0.417 /$ ton-hr to $\$ 0.377 /$ ton-hr. According to Figure $11 \mathrm{~b}$, both AOC and ACC decrease with an increase in $T_{L T-E v a p}$. When $T_{L T-E v a p}$ increases from 
$223 \mathrm{~K}$ to $243 \mathrm{~K}$, AOC and ACC decrease from $\$ 203,496$ to $\$ 176,117$ and from $\$ 211,072$ to $\$ 199,513$, respectively. Figure 11c shows that an increase in $T_{L T-E v a p}$ causes a reduction in $\dot{W}_{L T-C o m p}$ and $\dot{W}_{H T-C o m p}$ from $80.7 \mathrm{~kW}$ to $47 \mathrm{~kW}$ and from $280.7 \mathrm{~kW}$ to $248.2 \mathrm{~kW}$, respectively.

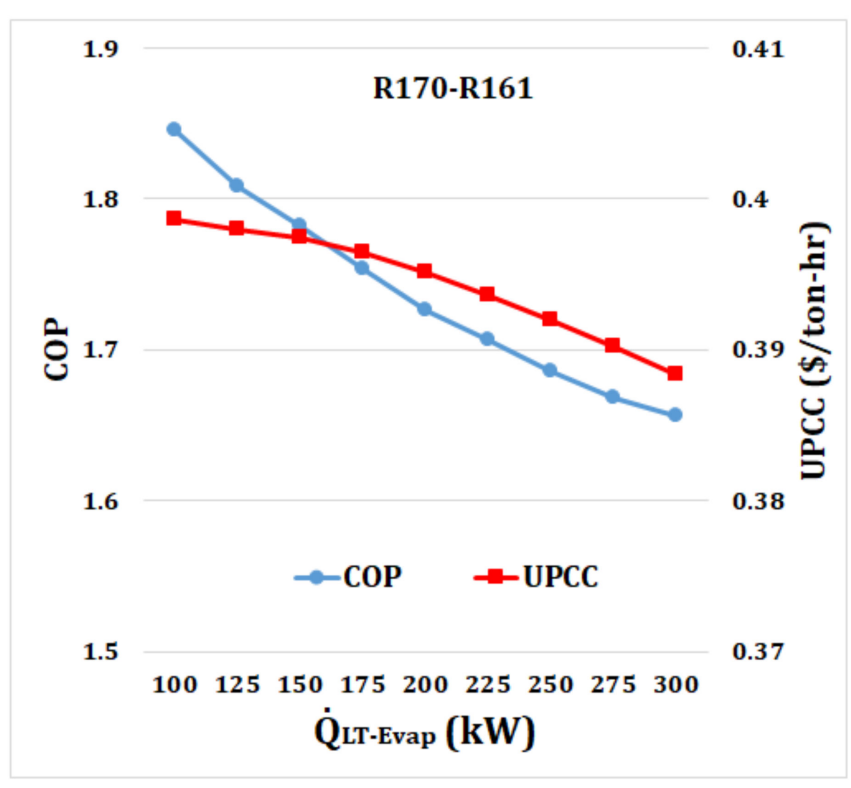

(a)

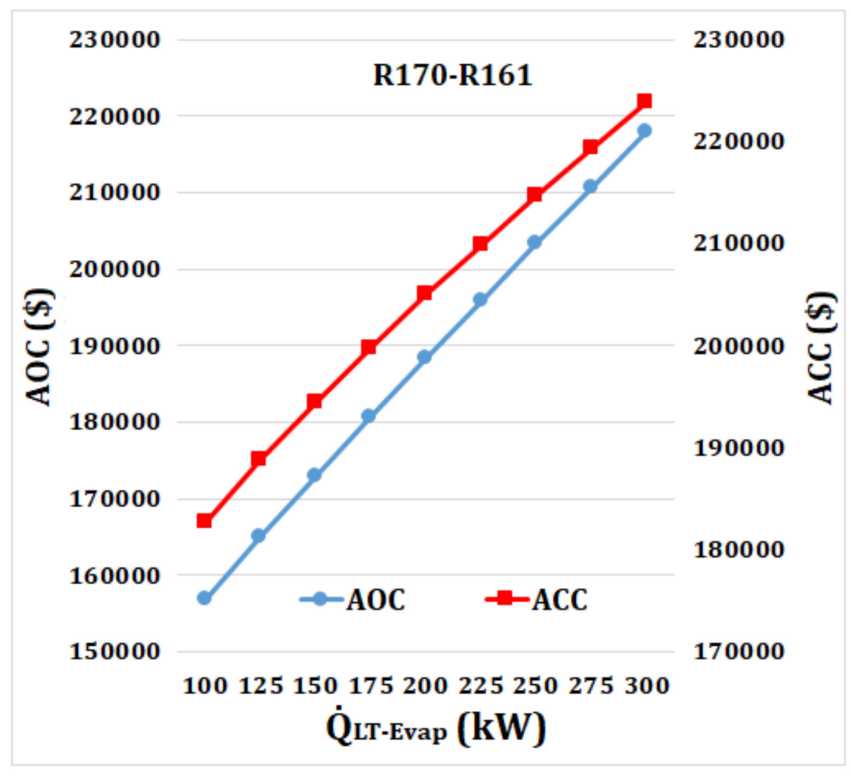

(b)

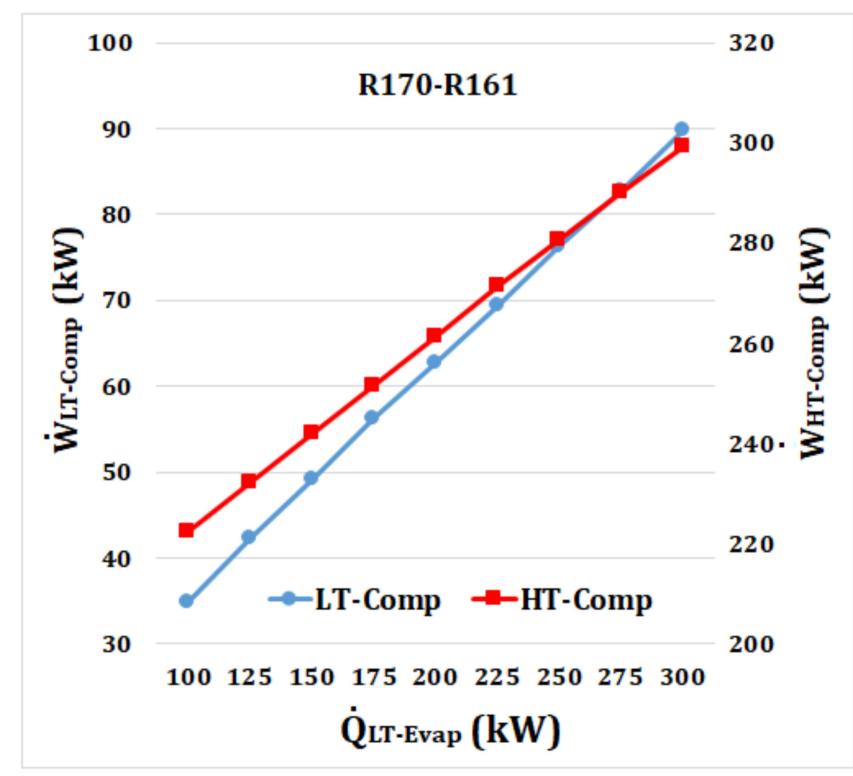

(c)

Figure 13. Effect of $\dot{Q}_{L T-E v a p}$ on (a)COP and UPCC, (b) AOC and ACC, and (c) $\dot{W}_{L T-C o m p}$ and $\dot{W}_{H T-C o m p}$ of the optimized cycle using R170-R161 refrigerant pair.

Figure 12 shows the influence of a change in $T_{H T-E v a p}$ on different parameters. The presented results show that the trend of increasing and decreasing of the parameters with $T_{H T-E v a p}$ is relatively similar to that of $T_{L T-E v a p}$. The optimum values of $\Delta T_{C a s}$ and $T_{C a s}$ have a slight change with an increase in $T_{H T-E v a p} . \Delta T_{C a s}$ increases from $4.61 \mathrm{~K}$ to $4.69 \mathrm{~K}$ and $T_{\text {Cas }}$ decreases from $273.89 \mathrm{~K}$ to $271.15 \mathrm{~K}$, respectively. According to Figure $12 \mathrm{a}$, an increase in $T_{H T-E v a p}$ from $243 \mathrm{~K}$ to $263 \mathrm{~K}$ results in increasing COP from 1.528 to 1.959 and decreasing UPCC from $\$ 0.422 /$ ton-hr to $\$ 0.371 /$ ton-hr. Figure $12 \mathrm{~b}$ shows that AOC and 
ACC decrease from $\$ 209,302$ to $\$ 169,809$ and from $\$ 210,866$ to $\$ 199,442$, respectively. As shown in Figure 13c, with an increase in $T_{H T-E v a p}$ from $243 \mathrm{~K}$ to $263 \mathrm{~K}$ both $\dot{W}_{L T-C o m p}$ and $\dot{W}_{H T-\text { Comp }}$ reduce from $66.5 \mathrm{~kW}$ to $59.7 \mathrm{~kW}$ and from $311.7 \mathrm{~kW}$ to $217.5 \mathrm{~kW}$, respectively.

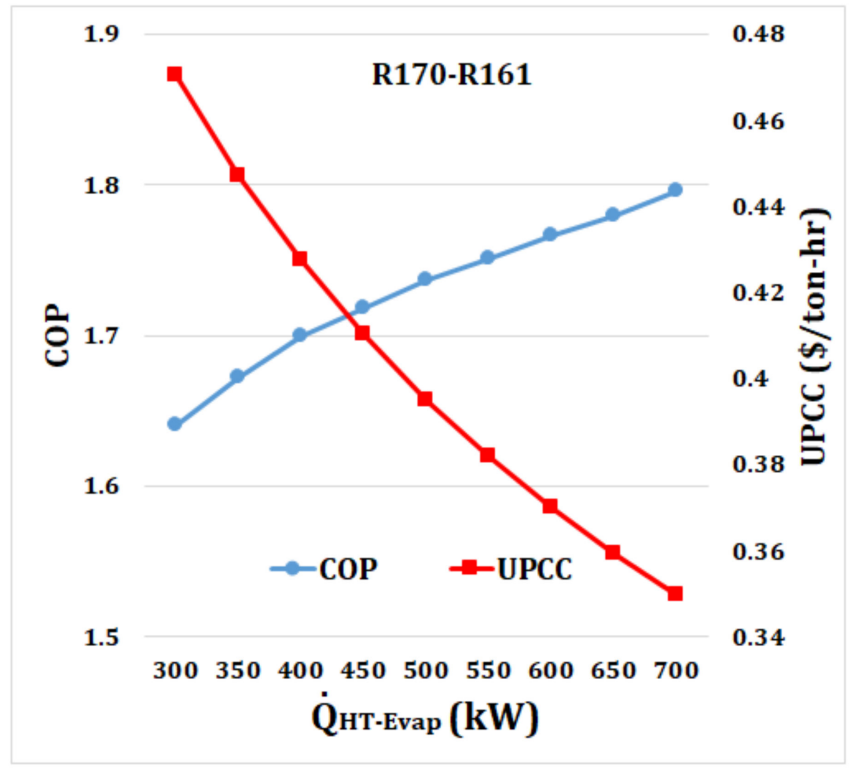

(a)

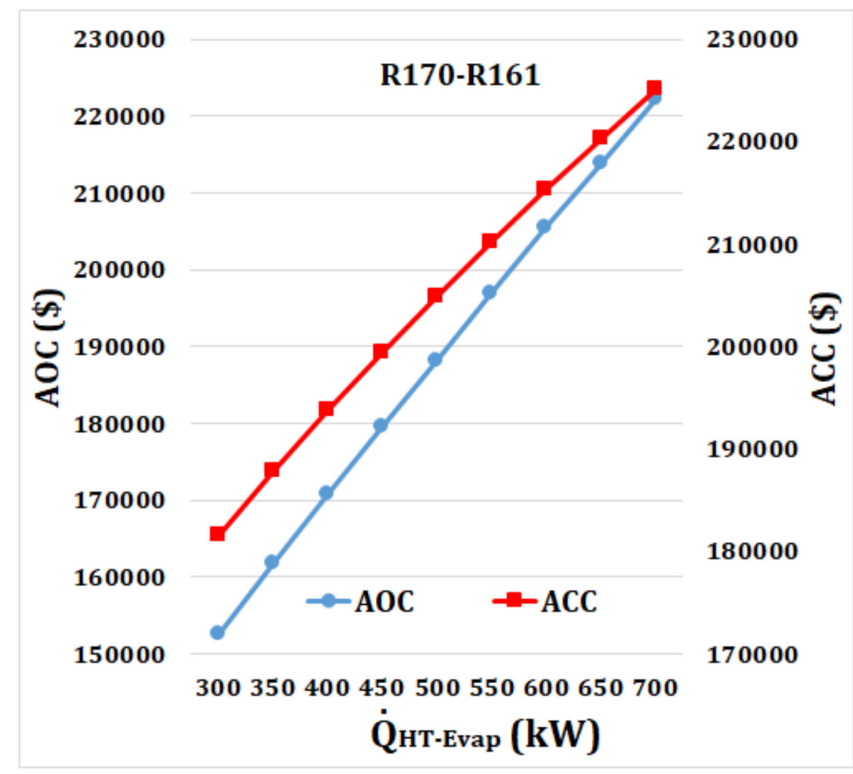

(b)

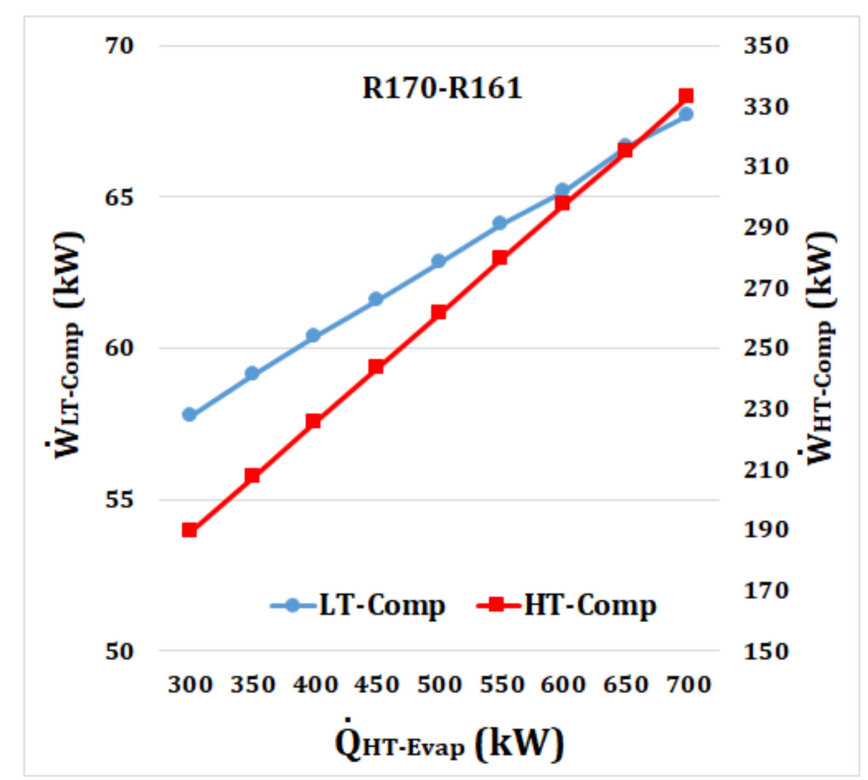

(c)

Figure 14. Effect of $\dot{Q}_{H T-E v a p}$ on (a) COP and UPCC, (b) AOC and ACC, and (c) $\dot{W}_{L T-C o m p}$ and $\dot{W}_{H T-C o m p}$ of the optimized cycle using R170-R161 refrigerant pair. 
In all previous analyses of this study, $\dot{Q}_{L T-E v a p}$ and $\dot{Q}_{H T-E v a p}$ were set fixed at $200 \mathrm{~kW}$ and $500 \mathrm{~kW}$, respectively. It is, however, interesting to examine the influence of $\dot{Q}_{L T-E v a p}$ and $\dot{Q}_{H T-E v a p}$ on different thermodynamic and economic parameters of the cascade refrigeration cycle. With an increase in $\dot{Q}_{L T-E v a p}$, the optimum values of $\Delta T_{C a s}$ and $T_{C a s}$ vary from $4.48 \mathrm{~K}$ to $4.63 \mathrm{~K}$ and from $275.1 \mathrm{~K}$ to $271.2 \mathrm{~K}$, respectively. Figure 13a shows the influence of a change in $\dot{Q}_{L T-E v a p}$ on COP and UPCC. The results show that with an increase in $\dot{Q}_{L T-E v a p}$, COP and UPCC decrease, but with a different trend. When $\dot{Q}_{L T-E v a p}$ increases from $100 \mathrm{~kW}$ to $300 \mathrm{~kW}$, COP and UPCC decrease from 1.845 to 1.656 and from $\$ 0.398$ /ton-hr to $\$ 0.388 /$ ton-hr, respectively. As shown in Figure 13b, both AOC and ACC increase from $\$ 156,737$ to $\$ 217,859$ and from $\$ 182,650$ to $\$ 223,824$, respectively. According to Figure $13 c, \dot{W}_{L T-C o m p}$ and $\dot{W}_{H T-C o m p}$ both increase with an increase $\dot{Q}_{L T-E v a p}$ due to an increase in the size of the refrigeration system. $\dot{W}_{L T-C o m p}$ increases from $34.9 \mathrm{~kW}$ to $89.7 \mathrm{~kW}$ and $\dot{W}_{H T-C o m p}$ increases from $222.5 \mathrm{~kW}$ to $299.4 \mathrm{~kW}$.

With an increase in $\dot{Q}_{L T-E v a p}$, the size of the LT and HT cycles and the amounts of $\dot{W}_{L T-C o m p}$ and $\dot{W}_{H T-C o m p}$ increase. As the increase in $\dot{W}_{L T-\text { Comp }}$ and $\dot{W}_{H T-C o m p}$ outweighs the increase in $\dot{Q}_{L T-E v a p}$, the COP decreases with an increase in $\dot{Q}_{L T-E v a p}$. The AOC value increases because of an increase in $\dot{W}_{L T-C o m p}$ and $\dot{W}_{H T-C o m p}$ and the power requirement of the condenser and LT-Evap. Also, the ACC increases because of an increase in the size of the LT and HT cycles. The increase in the AOC and ACC values is less than the increase in $\dot{Q}_{L T-E v a p}$, resulting in a decrease in the UPCC of the cycle.

Figure 14 shows the impact of $\dot{Q}_{H T-E v a p}$ on different thermodynamic and economic parameters of the cascade refrigeration cycle. With a variation of $\dot{Q}_{H T-E v a p}$ from $300 \mathrm{~kW}$ to $700 \mathrm{~kW}$, the optimum values of $\Delta T_{C a s}$ and $T_{C a s}$ vary from $4.69 \mathrm{~K}$ and $4.64 \mathrm{~K}$ and from $270.3 \mathrm{~K}$ to $274.3 \mathrm{~K}$, respectively. Based on the results of Figure $14 \mathrm{a}$, with an increase in $\dot{Q}_{H T-E v a p}$ from $300 \mathrm{~kW}$ to $700 \mathrm{~kW}$, COP increases from 1.640 to 1.796 while UPCC decreases from $\$ 0.470 /$ ton-hr to $\$ 0.350 /$ ton-hr. According to Figure $14 \mathrm{~b}, \mathrm{c}$, with an increase in $\dot{Q}_{H T-E v a p}, \mathrm{AOC}, \mathrm{ACC}, \dot{W}_{L T-C o m p}$, and $\dot{W}_{H T-C o m p}$ have a similar trend as those of Figure 13b,c. Figure 14b shows both AOC and ACC experience a significant increase from $\$ 152,699$ to $\$ 222,312$ and from $\$ 181,603$ to $\$ 225,132$, respectively when $\dot{Q}_{H T-E v a p}$ increases from $300 \mathrm{~kW}$ to $700 \mathrm{~kW}$. As shown in Figure $14 \mathrm{c}, \dot{W}_{L T-C o m p}$ and $\dot{W}_{H T-C o m p}$ have an increasing trend from $57.8 \mathrm{~kW}$ to $67.7 \mathrm{~kW}$ and from $189.2 \mathrm{~kW}$ to $332.8 \mathrm{~kW}$, respectively.

An increase in $\dot{Q}_{H T-E v a p}$ causes an increase in the size of the HT cycle and the amount of $\dot{W}_{H T-C o m p}$. With an increase in $\dot{Q}_{H T-E v a p}$, the optimum value of $T_{\text {Cas }}$ increases, which leads to increasing the temperature gap between LT-Evap and the cascade heat exchanger (or the condenser of the LT cycle) and consequently increasing the $\dot{W}_{L T-C o m p}$. The increase in $\dot{Q}_{H T-E v a p}$ outweighs the increase in $\dot{W}_{L T-C o m p}$ and $\dot{W}_{H T-C o m p}$, resulting in an increase in the COP of the cascade cycle. With an increase in $\dot{Q}_{H T-E v a p}$, the AOC increases because of an increase in $\dot{W}_{L T-C o m p}$ and $\dot{W}_{H T-C o m p}$ and the power requirement of the condenser and HT-Evap. Also, the ACC increases because of an increase in the cycle's size. The UPCC of the cycle decreases because the increase in the AOC and ACC is lower than the increase in $\dot{Q}_{H T-E v a p}$. 


\section{Conclusions}

In this work, a comprehensive thermodynamic and economic analysis was carried out to investigate the potential of using 18 environmentally friendly refrigerant pairs in a dual-evaporator cascade refrigeration system and identify the most suitable refrigerant couple. The main concluding remarks are presented below.

According to the thermodynamic and economic findings, for all examined design and operating conditions, the R170-R161 pair and R1150-R1234yf pair were identified as the best and worst pairs, respectively. For the base case analysis, the COP of the R170-R161 and R1150-R1234yf pair was obtained as 1.727 and 1.552, respectively, and their UPCC was $\$ 0.395 /$ ton-hr and $\$ 0.419 /$ ton-hr, respectively. The difference between the thermodynamic and economic performance of the examined refrigerant pairs was because of their different thermophysical properties. The study results demonstrated that using the R170-R161 pair showed an improvement over R717-R744, normally used as a refrigerant pair of cascade refrigeration cycles.

The parametric study results showed that with an increase in $\Delta T_{C a s}$, the COP of all refrigerant pairs decreases significantly with almost the same trend. An increase in $\Delta T_{\text {Cas }}$ caused that the UPCC decreased first and then increased. For all refrigerant pairs, an increase in $T_{C a s}$ caused that the COP increased initially and then decreased while UPCC had a decreasing and increasing pattern with a variation in $T_{C a s}$. These decreases and increases patterns were found to be different for each refrigerant pair, due to their different thermophysical properties. For each refrigerant pair, the minimum UPCC was obtained at a specific value of $T_{C a s}$, indicating that the same $T_{C a s}$ cannot be used for all refrigerant pairs. An increase in $T_{L T-E v a p}$ and $T_{H T-E v a p}$ caused an increase in the COP and a decrease in the UPCC of all refrigerant pairs.

Optimization using a PSO algorithm was made to optimize the cycle by minimizing the UPCC for R170-R161 as the most suitable refrigerant pair. The influence of different parameters including $T_{\text {Cond }}, T_{L T-E v a p}, T_{H T-E v a p}, \dot{Q}_{L T-E v a p}$, and $\dot{Q}_{H T-E v a p}$ was further investigated on the performance of an optimized cycle that used R170-R161 refrigerant pair. It was found that variation of $T_{\text {Cond }}$ and $T_{H T-E v a p}$ had the most influence on the performance of the optimized cycle.

In summary, this study provided useful insight regarding the best refrigerant pair and the importance of the proper selection of refrigerant pairs on the economic and environmental performance of a dual-evaporator cascade refrigeration cycle to maximize the efficiency and minimize the cost and negative environmental impacts.

Future studies should focus on more detailed analysis and equipment sizing and selection of the dual-evaporator cascade refrigeration cycle that used the R170-R161 pair. Furthermore, in future studies, dynamic analysis of the system under variable loads should be conducted and proper control strategies should be developed to ensure the proper operation of the system under variable loads.

Author Contributions: K.M.: Conceptualization, Methodology, Software, Validation, Formal analysis, Investigation, Resources, Data Curation, Writing-Original Draft, Writing-Review \& Editing, Visualization, Supervision, Project administration; K.M.P.: Conceptualization, Investigation, WritingReview \& Editing, Supervision, Project administration, Funding acquisition. All authors have read and agreed to the published version of the manuscript.

Funding: This research was funded by the U.S. Department of Energy, grant number DE-EE0007712.

Institutional Review Board Statement: Not applicable.

Informed Consent Statement: Not applicable.

Acknowledgments: The authors are grateful for the funding sources provided by the U.S. Department of Energy's Office of Energy Efficiency and Renewable Energy under Grant Number DE-EE0007712.

Conflicts of Interest: The authors declare no conflict of interest. 


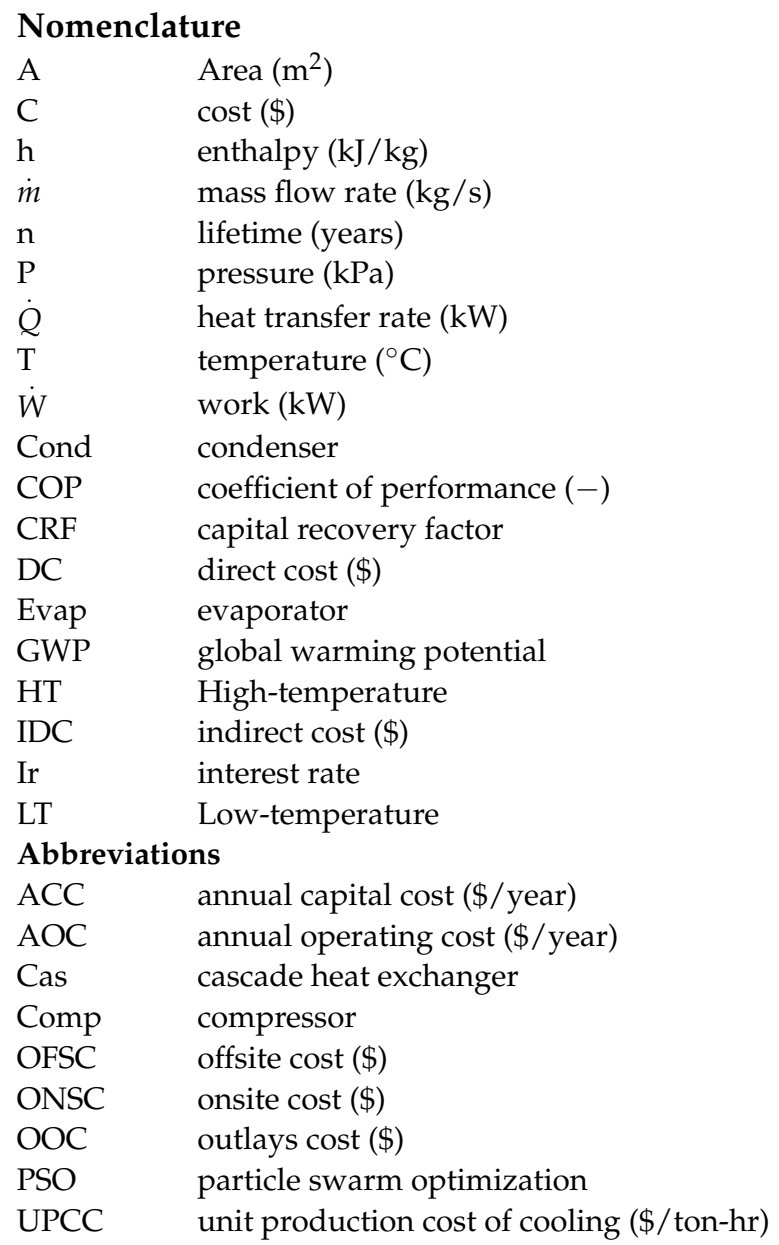

\section{References}

1. Markets and Markets. Industrial Refrigeration System Market by Component (Compressor, Condenser, Evaporator), Refrigerant Type (Ammonia, CO2), Application (Fruit \& Vegetable Processing, Meat \& Poultry, Refrigerated Warehouse), and Region-Global Forecast to 2025. 2020. Available online: https:/ / www.marketsandmarkets.com/pdfdownloadNew.asp?id=245749288 (accessed on 15 January 2021).

2. Carbon Trust. Net Zero Cold Chains for Food. 2020. Available online: https://prod-drupal-files.storage.googleapis.com/ documents /resource/public/Net_zero_cold_chains_for_food.pdf (accessed on 15 January 2021).

3. Pendurthi, M.; Pelluru, V.; Chilakapati, A.; Dandotiya, D.; Banker, N.D. Performance Investigation of a Vapor Adsorption Refrigeration System Based on Adsorption/ Desorption Time and Heat Transfer. J. Thermal Sci. Eng. Appl. 2021, $13,51024$. [CrossRef]

4. Abbaz, D.; Chaker, A.; Bourouis, M. Performance Analysis of a Cascading Adsorption Cycle Powered by High-Temperature Heat Sources for Low-Temperature Cooling in Hot Climates. J. Thermal Sci. Eng. Appl. 2020, 12, 51021. [CrossRef]

5. Llopis, R.; Calleja-Anta, D.; Maiorino, A.; Nebot-Andrés, L.; Sánchez, D.; Cabello, R. TEWI analysis of a stand-alone refrigeration system using low-GWP fluids with leakage ratio consideration. Int. J. Refrig. 2020, 118, 279-289. [CrossRef]

6. Nemati, A.; Nami, H.; Yari, M. A comparison of refrigerants in a two-stage ejector-expansion transcritical refrigeration cycle based on exergoeconomic and environmental analysis. Int. J. Refrig. 2017, 84, 139-150. [CrossRef]

7. Massuchetto, L.H.P.; do Nascimento, R.B.C.; de Carvalho, S.M.R.; de Araújo, H.V.; d'Angelo, J.V.H. Thermodynamic performance evaluation of a cascade refrigeration system with mixed refrigerants: R744/R1270, R744/R717 and R744/RE170. Int. J. Refrig. 2019, 106, 201-212. [CrossRef]

8. Wang, W.; Zhou, Q.; Tian, G.; Hu, B.; Li, Y.; Cao, F. The intermediate temperature optimization for cascade refrigeration system and air source heat pump via extreme seeking control. Int. J. Refrig. 2020, 117, 150-162. [CrossRef]

9. Bingming, W.; Huagen, W.; Jianfeng, L.; Ziwen, X. Experimental investigation on the performance of $\mathrm{NH}_{3} / \mathrm{CO}_{2}$ cascade refrigeration system with twin-screw compressor. Int. J. Refrig. 2009, 32, 1358-1365. [CrossRef]

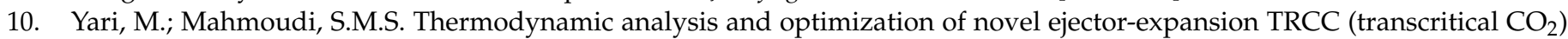
cascade refrigeration cycles (Novel transcritical CO2 cycle). Energy 2011, 36, 6839-6850. [CrossRef]

11. Sarkar, J.; Bhattacharyya, S.; Lal, A. Selection of suitable natural refrigerants pairs for cascade refrigeration system. Proc IMechE Part. A J. Power Energy. 2013, 227, 612-622. [CrossRef] 
12. Dokandari, D.A.; Setayesh Hagh, A.; Mahmoudi, S.M.S. Thermodynamic investigation and optimization of novel ejectorexpansion $\mathrm{CO} 2 / \mathrm{NH} 3$ cascade refrigeration cycles (novel CO2/NH3 cycle). Int. J. Refrig. 2014, 46, 26-36. [CrossRef]

13. Yilmaz, B.; Erdonmez, N.; Kemal Sevindi, M.; Mancuhan, E. Thermodynamic Analysis and Optimization of Cascade Condensing Temperature of a CO2(R744)/R404A Cascade Refriger-ation System. International Refrigeration and Air Conditioning Conference. 2014, Paper 1541. Available online: http:/ / docs.lib.purdue.edu/iracc/1541 (accessed on 21 January 2021).

14. Parmar, G.G.; Kapadia, R.G. Thermodynamic Analysis of Cascade refrigeration system using a natural refrigerants for supermarket application. Int. J. Innov. Res. Sci. Eng. Technol. 2015, 4, 1839-1846.

15. Llopis, R.; Sánchez, D.; Sanz-Kock, C.; Cabello, R.; Torrella, E. Energy and environmental comparison of two-stage solutions for commercial refrigeration at low temperature: Fluids and systems. Appl. Energy 2015, 138, 133-142. [CrossRef]

16. Llopis, R.; Sanz-Kock, C.; Cabello, R.; Sánchez, D.; Nebot-Andrés, L.; Catalán-Gil, J. Effects caused by the internal heat exchanger at the low temperature cycle in a cascade refrigeration plant. Appl. Therm. Eng. 2016, 103, 1077-1086. [CrossRef]

17. Mosaffa, A.H.; Garousi Farshi, L.; Infante Ferreira, C.A.; Rosen, M.A. Exergoeconomic and environmental analyses of $\mathrm{NH}_{3} / \mathrm{CO}_{2}$ cascade refrigeration systems equipped with different types of flash tank intercoolers. Energy Convers. Manag. 2016, 117, 442-453. [CrossRef]

18. Megdouli, K.; Ejemni, N.; Nahdi, E.; Mhimid, A.; Kairouani, L. Thermodynamic analysis of a novel ejector expansion transcritical CO2/N2O cascade refrigeration (NEETCR) system for cooling applications at low temperatures. Energy 2017, 128, 586-600. [CrossRef]

19. Sun, Z.; Wang, Q.; Xie, Z.; Liu, S.; Su, D.; Cuim, Q. Energy and exergy analysis of low GWP refrigerants in cascade refrigeration system. Energy 2019, 170, 1170-1180. [CrossRef]

20. Sun, Z.; Wang, Q.; Dai, B.; Wang, M.; Xie, Z. Options of low Global Warming Potential refrigerant group for a three-stage cascade refrigeration system. Int. J. Refrig. 2019, 100, 471-483. [CrossRef]

21. Patel, V.; Panchal, D.; Prajapati, A.; Mudgal, A.; Davies, P. An efficient optimization and comparative analysis of cascade refrigeration system using NH3/CO2 and C3H8/CO2 refrigerant pairs. Int. J. Refrig. 2019, 102, 62-76. [CrossRef]

22. Singh, K.K.; Kumar, R.; Gupta, A. Comparative energy, exergy and economic analysis of a cascade refrigeration system incorporated with flash tank (HTC) and a flash intercooler with indirect subcooler (LTC) using natural refrigerant couples. Sustain. Energy Technol. Assess. 2020, 39, 100716. [CrossRef]

23. Mohammadi, K.; Khaledi, M.S.E.; Powell, K. A novel hybrid dual-temperature absorption refrigeration system: Thermodynamic, economic, and environmental analysis. J. Clean. Prod. 2019, 233, 1075-1087. [CrossRef]

24. Sánchez, D.; Llopis, R.; Cabello, R.; Catalán-Gil, J.; Nebot-Andrés, L. Conversion of a direct to an indirect commercial (HFC134a $/ \mathrm{CO}_{2}$ ) cascade refrigeration system: Energy impact analysis. Int. J. Refrig. 2017, 73, 183-199. [CrossRef]

25. Mohammadi, K.; Saghafifar, M.; McGowan, J.G.; Powell, K. Thermo-economic analysis of a novel hybrid multigeneration system based on an integrated triple effect refrigeration system for production of power and refrigeration. J. Clean. Prod. 2019, 238, 117912. [CrossRef]

26. Available online: http://www.coolprop.org/fluid_properties/PurePseudoPure.html\#list-of-fluids (accessed on 16 March 2021).

27. CoolProp 6.4.1. Available online: http:/ / www.coolprop.org/ (accessed on 16 March 2021).

28. Adebayo, V.; Abid, M.; Adedeji, M.; Dagbasi, M.; Bamisile, O. Comparative thermodynamic performance analysis of a cascade refrigeration system with new refrigerants paired with $\mathrm{CO}_{2}$. Appl. Therm. Eng. 2021, 184, 116286. [CrossRef]

29. Mohammadi, K.; Powell, K. Thermodynamic and economic analysis of different cogeneration and trigeneration systems based on carbon dioxide vapor compression refrigeration systems. Appl. Therm. Eng. 2020, 164, 114503. [CrossRef]

30. Roy, R.; Bhowal, A.J.; Mandal, B.J. Thermoeconomic Analysis of Vapor Compression Refrigeration System With Dedicated Subcooler for High-Temperature Lift Applications. J. Thermal Sci. Eng. Appl. 2021, 13, 61005. [CrossRef]

31. Roy, R.; Bhowal, A.J.; Mandal, B.J. Exergy and Cost Optimization of a Two-Stage Refrigeration System Using Refrigerant R32 and R410A. J. Thermal Sci. Eng. Appl. 2020, 12, 31024. [CrossRef]

32. Mohammadi, K.; McGowan, J.G. A thermo-economic analysis of a combined cooling system for air conditioning and low to medium temperature refrigeration. J. Clean. Prod. 2019, 206, 580-597. [CrossRef]

33. Rashidi, J.; Yoo, C.K. A novel Kalina power-cooling cycle with an ejector absorption refrigeration cycle: Thermodynamic modelling and pinch analysis. Energy Convers. Manag. 2018, 162, 225-238. [CrossRef]

34. Smith, R. Chemical Process. Design and Integration; Wiley: Hoboken, NJ, USA, 2005.

35. Turton, R.; Bailie, R.C.; Whiting, W.B.; Shaeiwitz, J.A. Analysis, Synthesis, and Design of Chemical Processes, 3rd ed.; Pearson Education, Inc.: New York, NY, USA, 2009.

36. Seixas Gomes de Almeida, B.; Coppo Leite, V. Particle Swarm Optimization: A Powerful Technique for Solving Engineering Problems. Swarm Intelligence-Recent Advances. New Perspect. Appl. 2019. [CrossRef]

37. Abed, K.A.; Khalil, E.E.; Abouel-Fotouh, A.M.; El-Hariry, G.; Abd El Salam, L.O. Optimal design of a counter flow cooling tower using PSO algorithm for operating cost minimization. Appl. Therm. Eng. 2018, 143, 149-159. [CrossRef]

38. Mohammadi, K.; Ellingwood, K.; Powell, K. A novel triple power cycle featuring a gas turbine cycle with supercritical carbon dioxide and organic Rankine cycles: Thermoeconomic analysis and optimization. Energy Convers. Manag. 2020, $220,113123$. [CrossRef] 
39. Mohammadi, K.; Jiang, Y.; Borjian, S.; Powell, K. Thermo-economic assessment and optimization of a hybrid triple effect absorption chiller and compressor. Sustain. Energy Technol. Assess. 2020, 38, 100652. [CrossRef]

40. Antonio Messineo, A. R744-R717 Cascade Refrigeration System: Performance Evaluation compared with a HFC Two-Stage System. Energy Procedia 2012, 14, 56-65. [CrossRef] 